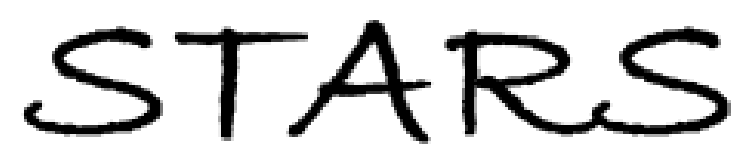

University of Central Florida

STARS

\title{
A Solid Phase Assay For Topoisomerase I Interfacial Poisons And Catalytic Inhibitors
}

Vidusha Cyril

University of Central Florida

Part of the Molecular Biology Commons

Find similar works at: https://stars.library.ucf.edu/etd

University of Central Florida Libraries http://library.ucf.edu

This Masters Thesis (Open Access) is brought to you for free and open access by STARS. It has been accepted for inclusion in Electronic Theses and Dissertations, 2004-2019 by an authorized administrator of STARS. For more information, please contact STARS@ucf.edu.

\section{STARS Citation}

Cyril, Vidusha, "A Solid Phase Assay For Topoisomerase I Interfacial Poisons And Catalytic Inhibitors" (2011). Electronic Theses and Dissertations, 2004-2019. 1836.

https://stars.library.ucf.edu/etd/1836

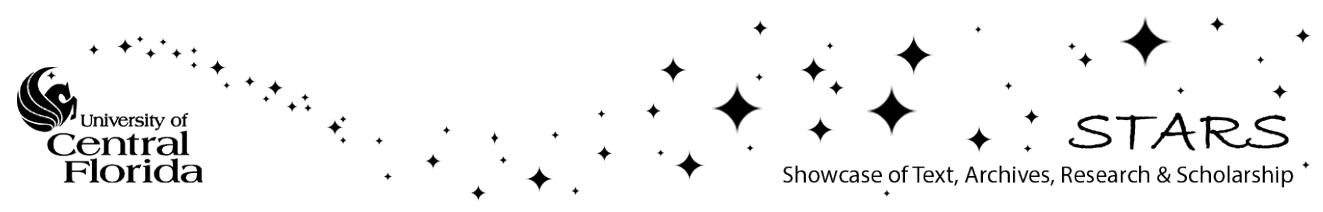




\title{
A SOLID PHASE ASSAY FOR TOPOISOMERASE I INTERFACIAL POISONS AND CATALYTIC INHIBITORS
}

by

\section{VIDUSHA CYRIL}

B.Tech. Sathyabama University, 2009

\author{
A thesis submitted in partial fulfillment of the requirements \\ for the degree of Master of Science in Molecular and Microbiology \\ in the Burnett School of Biomedical Sciences \\ in the College of Sciences \\ at the University of Central Florida \\ Orlando, Florida
}

Fall Term 2011

Major Professor: Mark. T. Muller 
(C) 2011 Vidusha Cyril 


\begin{abstract}
We report a mechanism based screening technique to rapidly identify eukaryotic topoisomerase I targeting agents. The method is based on genetic tagging of topoisomerase I to immobilize the enzyme on a solid surface in a microtiter well format. DNA is added to the wells and retained DNA is detected by Picogreen fluorescence. Compounds that result in an increase in Picogreen staining represent potential topoisomerase interfacial poisons while those that reduce fluorescence report catalytic inhibitors; therefore, the solid phase assay represents a 'bimodal' readout that reveals mechanisms of action. The method has been demonstrated to work with known interfacial poisons and catalytic inhibitors. In addition to specific topoisomerase targeting drugs, the method also weakly detects other relevant anticancer agents, such as potent DNA alkylating and intercalating compounds; therefore, topoisomerase I HTS represents an excellent tool for searching and identifying novel genotoxic agents. This method is rapid, robust, economical and scalable for large library screens.
\end{abstract}


Dedicated to my ever-loving parents who always had faith in me 


\section{ACKNOWLEDGMENTS}

First and foremost I would like to extend my gratitude to my mentor and advisor Dr. Mark. T. Muller for providing me an opportunity to work in his lab. For the guidance and continued support he has offered throughout the process. I would like to thank my committee members Dr. Debopam Chakrabarti, Dr. James Turkson and Dr. Jihe Zhao for all their insightful comments and suggestions. I would also like to thank my lab members Dr. Gun Lee, Joo Hee, Wanvipa Ruangpradit and Alex fagenson who have helped me to start my work with the lab and for the many intellectual discussions. A special thanks to Dr. Bongyong Lee for acquainting me with the lab techniques and gracious support. I would not be where I am today if not for a wonderful family (parents Cyril Sagayaraj \& Daisy Anne, brother Sandeep Vikash). Much appreciation to Mahadevan Vasudevan for his always encouraging words; Soumya Jaganathan for her intellectual inputs. And last but not the least my friends here in Orlando especially my roommates and friends (Ramya Nityanandam, Priyadarshini Ravindren, Priya Saikumar, Pavithra Maniprasad, Geetha Priya, Prabhu Doss, Sathish, Supreeth and Sai) who made me feel at home and were always there to help me in any situation. Thank you all souls who have knowing or unknowingly helped me.

And above all I thank the Almighthy for showering all His blessings. 


\section{TABLE OF CONTENTS}

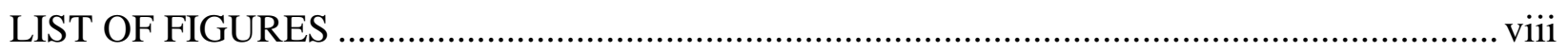

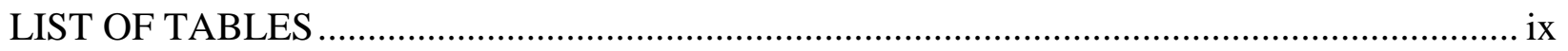

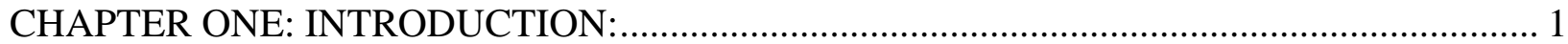

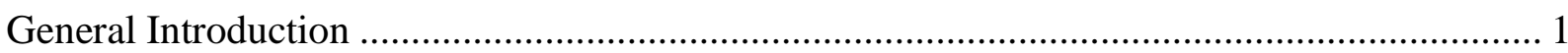

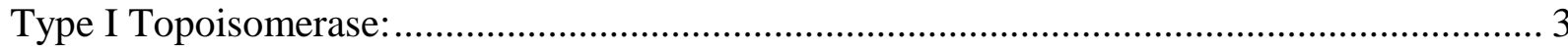

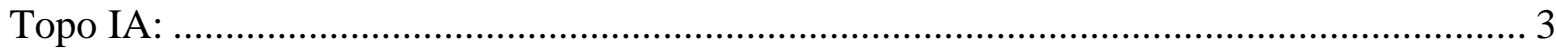

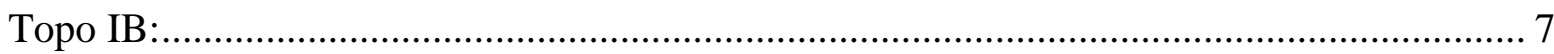

Topoisomerase as anti-cancer targets.............................................................................. 10

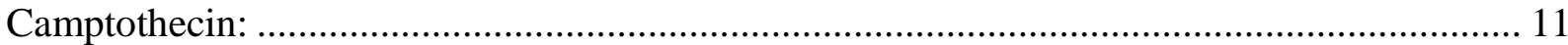

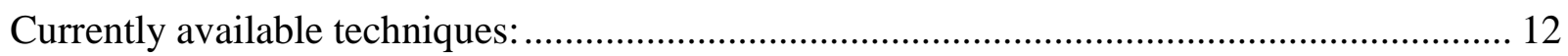

CHAPTER TWO: MATERIALS AND METHODS …………………………….................. 14

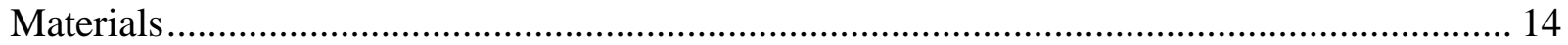

Purification of human topoisomerase I .......................................................................... 14

Plasmid relaxation and cleavage assays ....................................................................... 15

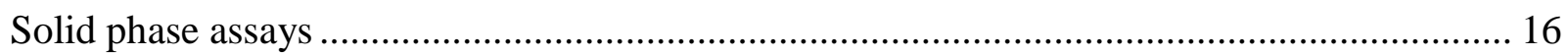

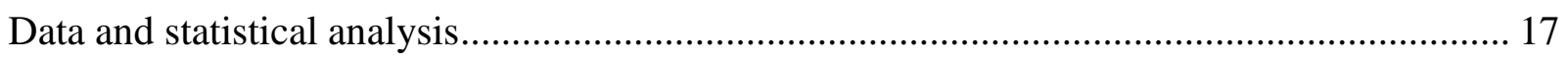

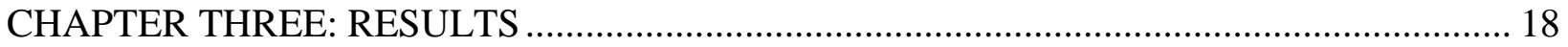

Immobilization of Topo I on Beads or Solid Phase and Activity Recovery ............................. 18

Topo I Cleavages in the Absence of CPT. ................................................................... 19

Detection of CPT Mediated Cleavage Complexes in the Solid Phase Assay ........................... 20

Termination, Optimization and Dose Dependence of Solid Phase Reactions ........................... 21

Heat Denatured Topo I is Inactive in Solid Phase Assays. .................................................... 22

Reconstruction and optimization of topo I HTS to detect IFP................................................. 23

Reconstruction and optimization of topo I HTS to detect CIC. .................................................. 23

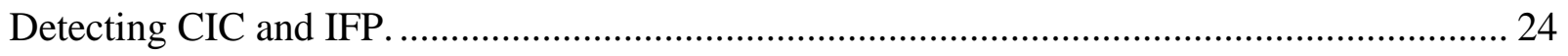

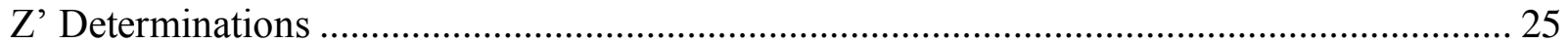




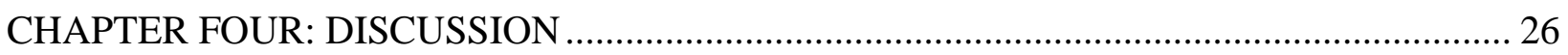

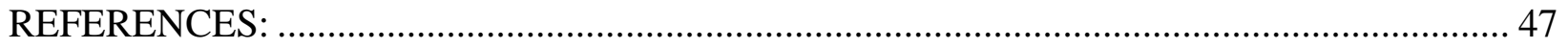




\section{LIST OF FIGURES}

Figure 1: Structure and mechanism of Topo IA …........................................................ 5

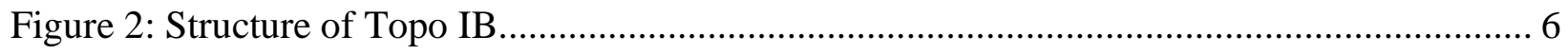

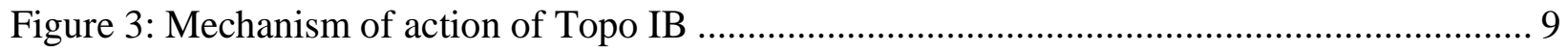

Figure 4: Purification of human topo I as a His tag product.............................................. 29

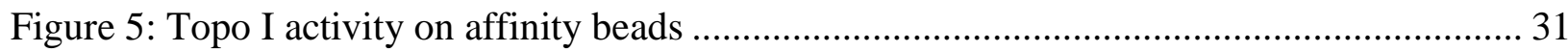

Figure 6: Analysis of Solid Phase and Liquid Phase Topo I Activity. .................................... 33

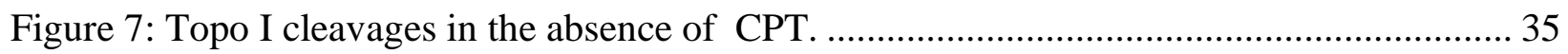

Figure 8: CPT Induced Cleavages in Solid Phase Assays .................................................. 37

Figure 9: Reaction termination and CPT Titration Data.................................................. 39

Figure 10: Native and denatured topo I and input DNA optimization. .................................. 41

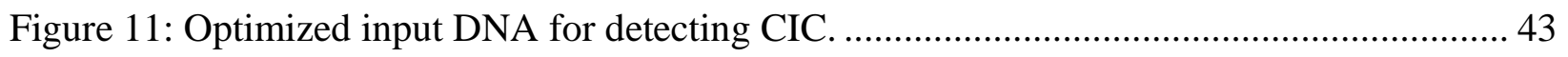




\section{LIST OF TABLES}

Table 1: Classification of Topoisomerase family …....................................................... 3

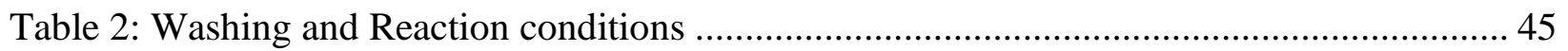

Table 3: Screening of Natural product set by HTS ........................................................... 46 


\section{CHAPTER ONE: INTRODUCTION:}

\section{General Introduction}

The double helical structure of the DNA as postulated by Watson and Crick in 1953 promotes genome stability by base stacking and hydrogen bonding. Though DNA is conceived in the one dimensional array it is present, expressed and functions in a three dimensional crowded cellular environment [1]. The semi-conservative model of DNA replication produces constraints on the topology of the parental DNA duplex [2]. DNA topology includes the supercoiling, interlocking of chains, catenanes and knots. In order to comprehend the topology of the DNA it is essential that one fully understand the concepts of (a) Linking Number, L; (b) Twist, T; (c) Writhing Number, W. Linking number is defined as a topological property of the DNA and is always an integer which gives the number of times one strand intersects with the other. Tw and $\mathrm{Wr}$ are given either a positive or negative sign. The sign is predicted depending on the conformation of the DNA, if for example the DNA is wound in the direction of helix it is positive supercoiling where the bases are held tightly and is difficult to separate them. If the supercoiling tends to unwind the right handed double helix then it is said to be negative supercoiling [3]. Linking number is an invariant value that cannot be changed without breaking either one of the strands followed by resealing [2]. Twist represents the helical turns around the central axis and corresponds to the Tw angle between base pairs in a DNA molecule. Writhing is the property of the double helix to form loops and coils when twisted around itself or around protein complexes as in nucleosomes. It is also a measure of superhelicity. When the DNA undergoes elastic deformations the linking number remains constant while $\mathrm{Wr}$ and $\mathrm{Tw}$ changes 
in such a way that their sum is constant and equal to linking number. The mathematical expression describing the relationship between them would be $\mathrm{Lk}=\mathrm{Tw}+\mathrm{Wr}[1,4-7]$.

It has been well established that various cellular processes such as transcription, replication, recombination, chromosome segregation and mitosis alter the dynamics of the template DNA producing overwinding (positive supercoiling), knots and catenanes. This has to be resolved for the survival of the cell and this is performed by the ubiquitous enzyme Topoisomerase [2, 8-12]. Topoisomerase action results in the formation of relaxed DNA, thermodynamically lowering the free energy state of the DNA which favors the separation of the two strands of the DNA [13]. All topoisomerases performs this by unique transesterification reaction using the tyrosine residue to create a transient nick on one or both the strands of the DNA and preserving the energy from the cleaved phosphodiester bond by forming covalent protein DNA complex. This reversible intermediate is known as the cleavage complex [14-16]. The enzyme then causes a controlled swivel like movement followed by religation of the strands. Topo mutants have shown growth arrests and impaired chromosome stability [17, 18]. Topoisomerase has been classified depending on their structural domains and mechanism of action. Topo I cleaves single strand DNA and catalyzes the relegation process, while Topo II introduces double strand breaks and passes the other segment. These enzymes are highly efficient in manipulating the DNA with very high fidelity utilizing either the energy stored in supercoiled DNA or by hydrolysis of ATP[17]. 


\section{Type I Topoisomerase:}

Topo I enzymes cleave one strand of DNA in an ATP independent manner. The uncoiling is driven by the torque in the DNA and hence the processivity of the enzyme decreases with the relaxation of the DNA. Based on the biochemical complexity and diversity of topo I catalyzed reaction and comprehensive structural analyses has facilitated further classification of topo I into IA and IB sub-families.

Table 1: Classification of Topoisomerase family

\begin{tabular}{|l|c|c|c|c|}
\hline \multirow{2}{*}{} & \multicolumn{3}{|c|}{ TOPOISOMERASE FAMILY } \\
\cline { 2 - 5 } & IA & IB & IIA & IIB \\
\hline Catalytic domains & Toprim/CAP & IB/Int & Toprim/CAP & Toprim/CAP \\
Mechanistic & Yes & No & Yes & Yes \\
properties & No & No & Yes & Yes \\
Metal dependent? & Single strand & Single strand & Double strand & Double strand \\
ATP dependent? & 5, & 3, & 5, & 5 \\
DNA cleavage & 5 & & \\
Cleavage polarity & & & & \\
\hline
\end{tabular}

Table adapted from [17].

\section{Topo IA:}

Type IA enzymes were first discovered by Wang in 1971, catalyze the relaxation of negatively supercoiled DNA generated by processes such as transcription and chromatin 
remodeling by altering the linking number in steps of one [19]. Positively supercoiled DNA or relaxed DNA are not substrates for type IA presumably because of the absence of single stranded regions in these structures. E.coli topo I and topo III, yeast DNA topo III, mammalian DNA topo III $\alpha$ and III $\beta$, eubacterial and archaeal reverse DNA gyrase are few examples of single chain monomeric type IA topoisomerase [20]. The ability of these enzymes to make single strand break in the absence of energy cofactor and attach to the 5' end of the broken strand has classified them as IA. However they slightly differ in the reactions they catalyze such as bacterial topo I are involved in relaxing supercoiled DNA while topo III plays an important role in decatenation process. Reverse gyrase is exceptional from other type IA in its requirement for ATP to positively supercoil the DNA of hyperthermophiles. It does so to protect the genome of bacteria thriving in very high temperature [21, 22].

The flattened toroidal structure of topo I has four distinct domains: Domain I consisting of the $\alpha / \beta$ "Rossmann-fold" similar to those found in the nucleotide binding proteins that catalyze the phosphodiester reactions, domain II consisting of small $\beta$ barrel sheets, and domains III and IV made up of the $\alpha$ helical structures [23]. Michel Duguet identified that topo IA family fold into a horse-shoe shaped structure with a positively charged central hole that accommodates the DNA which he describes as the 'topofold' [24]. Domains I and IV forms the base of a ringclamp and is attached to the mobile arch formed by domains II and III. The base harbors the CAP (catabolite activator protein) domain for nucleotide binding and the 'toprim' domain helps in strand rejoining [25]. The active site (Tyr 319) residue resides deeply buried in the domain III and interacts with other conserved residues. The close proximity of the acidic residues coordinate $\mathrm{Mg} 2+$ to assist in catalysis similar to those found in the klenow fragment. Though $\mathrm{Mg}$ is 
not required for activity it increases the kinetics of the reaction [26]. In the case of reverse gyrase an additional helicase domain consisting of RecA folds (binds to ATP) and latch domain is found [27].
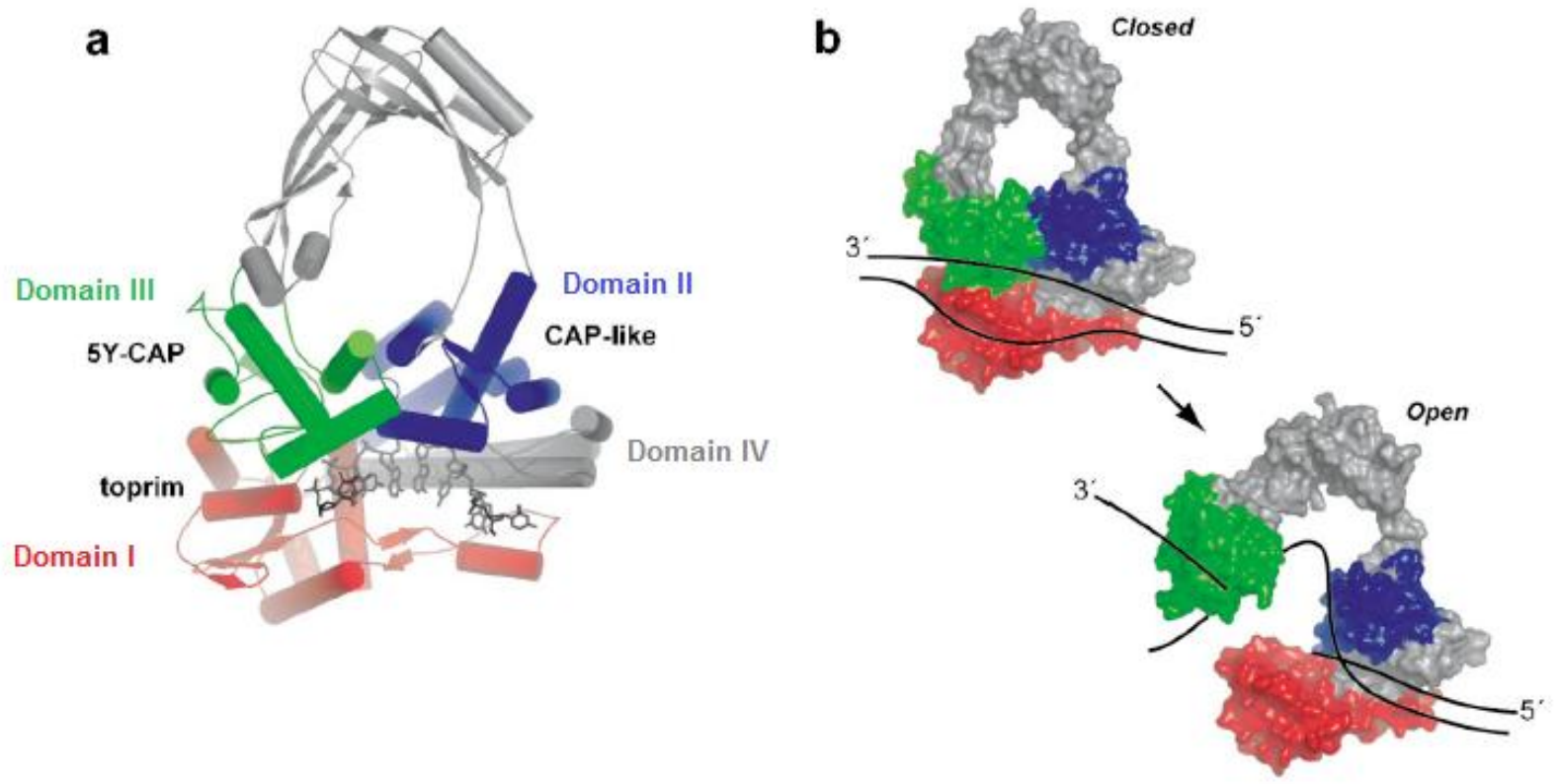

Figure 1: Structure and mechanism of Topo IA

A. Overall structure of E. coli topo III bound to the DNA. The different structural domains are indicated in different colors. B. Crystal structure of E.coli topo I illustrating the enzyme bridge mechanism of topo I [17].

Type IA and II vary in their ability to cleave either single or double strands of DNA; however both of them use the "enzyme bridge mechanism". In which a nick is created in the strand the gap is opened between them and allows the second DNA strand or duplex segment to pass through it [23]. The interface of domain III and I forms a gating system to regulate the passage of the DNA strands. Following cleavage the 5' of the broken strand remains attached to 
the active site and the other end remains non-covalently tethered. The second intact strand or duplex is transported across the bridge. Following the entry of the segment into the central hole of the N-terminal fragment, the broken strand is rejoined and the second strand exits without passing through the rejoined strand [17, 19, 23, 28-31].

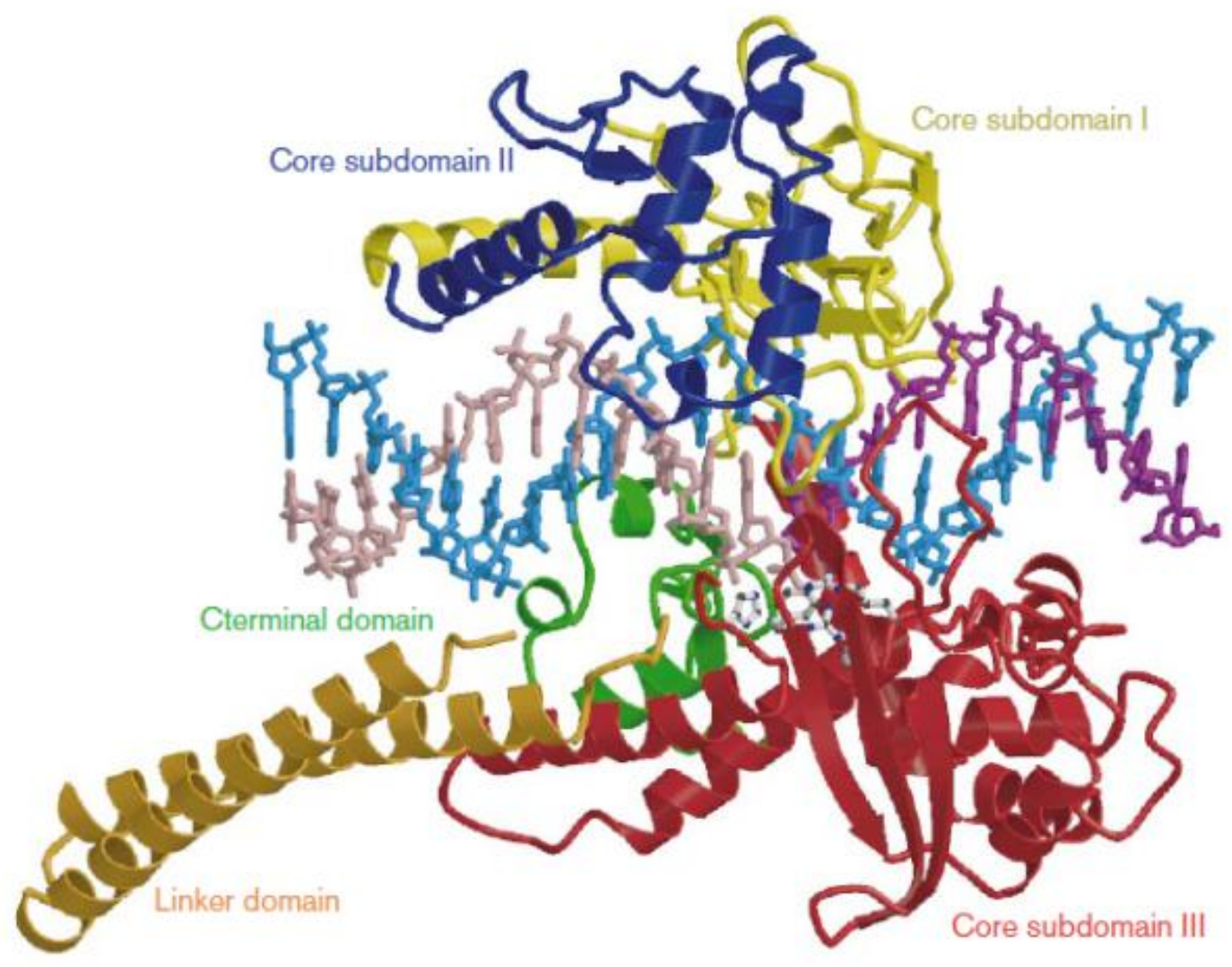

Figure 2: Structure of Topo IB

A 2.8 A resolution of the $70 \mathrm{kDa}$ form of the human topoisomerase I in a non covalent complex with the DNA [32] 


\section{Topo IB:}

Type IB structurally differ from IA in that they catalyze the relaxation of both negatively and positively supercoiled DNA altering the linking number by up to five turns per reaction cycle. They are $80-110 \mathrm{kDa}$ in size and are mostly found in eukaryotic cells, with one exception being vaccinia virus. Topo IB cleave single strand of DNA in the absence of any metal cation or energy cofactor and covalently attaches to the 3 ' end of the DNA [28, 32]. They share structural similarities with tyrosine recombinases and integrases catalytic domain. They also perform similar functions except for the fact topo IB exists in monomeric form cleaving single strand and has additional domains that help in rotating the DNA [33]. Human topoI, vaccinia topo I and hyperthermophilic eubacterial DNA topoV belong to topo IB family [20]. Its role has been found essential in processes such as transcription and mitrocondrial replication.

The crystal structure of topo IB consists of four major domains: N-terminal domain $(\sim 24 \mathrm{kDa})$, core domain $(\sim 54 \mathrm{kDa})$, Linker domain $(\sim 3 \mathrm{kDa})$ and C-terminal domain $(\sim 10 \mathrm{kDa})$. The N-terminal unconserved domain is protease sensitive, is highly charged and does not play a role in the relaxation of DNA. It has the nuclear localization signals and interacts with a number of other cellular proteins especially with rDNA and organelle responsible for the synthesis of ribosome [34]. Despite the linker domains potential role in DNA binding, it is dispensable for topo activity. The core domain is further divided in to three subdomains based on the structural organization designated as I, II and III. The core domain and the C-terminal domain are the highly conserved catalytically active domain and executes the cleavage, relegation transesterification reactions [35] 
The human topo IB is a bi-lobed structure that looks similar to a hand encompassing the DNA structure. Subdomain I and II consists of two unique helices termed as the "nose cone". They make up the upper region of the lobe or "cap" of the enzyme, while subdomain III and Cterminal domain forms the lower region. The cap and base interact with each other via two opposing loops referred to as the 'lips' which is the only point of contact and is made up of only 6 amino acids and one salt bridge. The opening and closing of the clamp is facilitated by a hinge [36]. The C-terminal domain is the catalytically active domain and consists of 5 conserved residues: two arginine residues (Arg488 and Arg590), a lysine (Lys532), a histidine residue (His 632) and the Tyr723. Upon binding to the DNA, four of the conserved residues in the active site acts to position the nucleophilic Tyr723 to attack the scissile phosphate. This leads to the formation of covalent topoisomerase-DNA complex referred to as the "cleavage complex". The tetrad helps in stabilization of the transition state. The Lys532 and Arg488 have been implicated in a "proton relay" mechanism, co operating both in deprotonation of Tyr 723 for attack and in protonation of the 5' $\mathrm{OH}$ group of the non-bridging oxygen. Subsequently the second nucleophilic attack by the $5^{\prime} \mathrm{OH}$ relieves the enzyme and reseals the nicked DNA producing a relaxed DNA helix. Thus the constellation of residues helps in coupling the relaxation providing a flexible conformation to the enzyme [17, 32, 37-39].

A 'controlled rotation' mechanism has been proposed to explain the relaxation of DNA by topo IB changing the linking number more than one. In this, the lower part of the cleaved strand rotates over the intact strand. The cap along with the linker region influence rotation by interacting with the downstream region of the DNA and are maintained in the closed state to prevent extensive rotation of the DNA strand. The relaxation of the DNA is governed by the 
friction caused by interaction of the DNA with the protein and the torque stored in the supercoiled DNA. The number of supercoils released by the enzyme follows an exponential distribution i.e. more the twists, greater the number of released supercoils [40-42] .

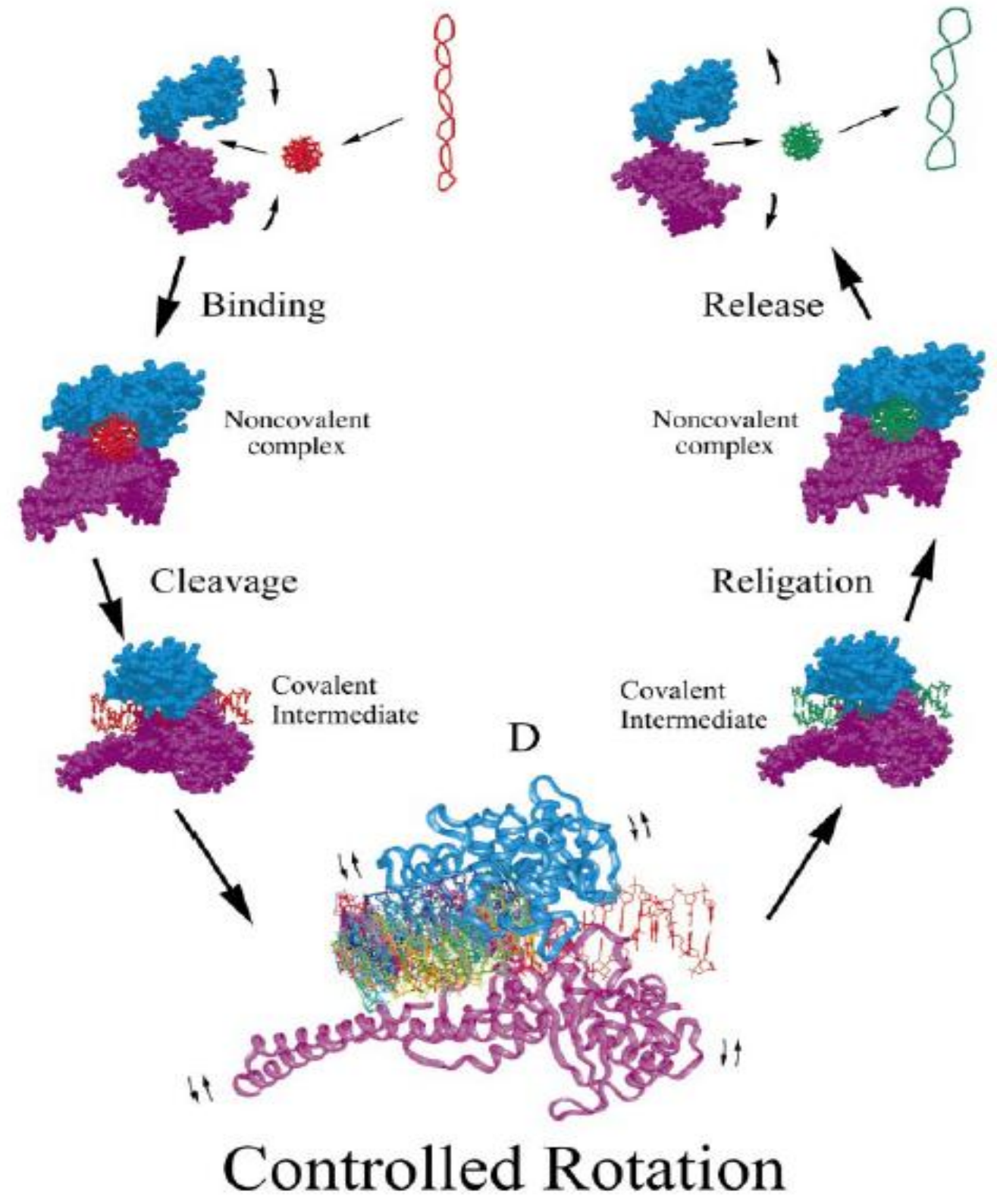

Figure 3: Mechanism of action of Topo IB

Figure adapted from [43] 


\section{Topoisomerase as anti-cancer targets}

Topoisomerases are essential for the survival of various cellular organisms which helps maintain the integrity and the structure of the DNA. Topo I is found to be heavily enriched in the nucleolus of the transcriptionally active cell due to high rate of processes such as replication and transcription taking place at those sites. Topo I is found to be catalytically inactive in dormant cells. Through its effect on DNA supercoiling, topo I is involved in gene regulation by discriminating the promoter regions to be transcribed [44]. The critical feature common to all topoisomerase is the formation of the "covalent cleavage complex" during strand passage event. Under normal physiological state these complexes are transitory intermediates and present in low concentrations which are tolerated by the cell. However events that significantly increases their concentration results in failure to complete the reaction cycle and discontinuity in the DNA/RNA, which imposes deleterious effect on the cell if not repaired efficiently [45]. It is speculated that the healthy cells in response to DNA lesions employ Tdp1 and SSBR to remove the peptide bound to the DNA followed by ubiquitination and degradation by the $26 \mathrm{~S}$ proteosome [46]. This is not the case in most of the cancerous cells which have elevated levels of topo I and are defective in their repair mechanism increasing their responsiveness to treatments $[47,48]$. The chromosomal insults and induction of recombination/ repair pathway triggers chromosomal translocations and mutations. Significant accumulation of these aberration results in the nucleolar disruption and stabilization of p53 in the nucleus leading to cell cycle arrest and apoptosis [49-51]. 
The Topoisomerase inhibitors have gained wide clinical significance as anti bacterial and anticancer therapeutics. Drugs targeting topo I may act by two non-mutually exclusive mechanisms; i) Drugs can act by impairing the religation of the cleaved strand. These drugs are known as the 'interfactial poisons (IFP)', due to their mechanism that stabilizes and increases the ternary complex by altering topo-DNA interaction and generates strand breaks inducing lethal events[1]. ii) Drugs that do not stabilize the cleavage complex but rather inhibit the catalytic activity of strand passing by topoI are known as 'inhibitors' [45]. There are a large number of topo I interfacial poisons IFP, including camptothecin, indolarbazoles, NSC314622, indenoisoquinolines, among many others [52]. Hypersensitivity of the cells to the poisons increases with overexpression of topoisomerase, while reduction leads to drug resistance. Conversely decreased concentration of topo I in the cell increases sensitivity to inhibitors. This leads to lack of interaction between the enzyme and drug and hence diminishes the antitumor effects $[53,54]$.

\section{Camptothecin:}

Camptothecin is a plant alkaloid isolated from the stem wood of the Chinese tree Camptotheca acuminata. It possesses a novel ring system exhibits potent antileukemic and antitumor activities in animals [55]. Interestingly CPT by itself does not cleave DNA rather interferes with the breakage-reunion reaction of topo I, trapping the cleavage complex indicating that the drug mediated toxicity is mediated through topo I [56]. Strucuture activity study of camptothecin on topo I revealed that drugs with this symmetry inhibit relaxation binding to the minor groove of the DNA causing bending of the DNA helical axis preventing ligation of the 
broken ends. This produces nicked open circles which is reversible upon removal of the drug unless otherwise it collides with the replication machinery. Camptothecin is known to inhibit both the RNA and DNA synthesis. The inhibition of RNA synthesis and fragmentation of chromosomal DNA can be rapidly reversed upon removal of the drug. On the other hand, the inhibition of DNA synthesis is only partially reversed. [57-61]. The cytotoxicity of camptothecin is S-phase specific and results when the trapped cleavage complex is traversed by the replicationary machinery or helicases $[60,62]$. Drug induced DNA damage triggers the conjugation of topo I with SUMO, a ubiquitin like protein by UBC9 and downregulation of topo I $[63,64]$. Ubiquitinated proteins are then targeted to destruction by the $26 \mathrm{~S}$ proteosome [65].

Despite the impressive efficacy of CPT there are certain limitations associated with their clinical application. The biological activity of CPT depends on the chemical reactivity of the closed lactone ring structure which is poorly soluble. Nevertheless, the hydrolysis of CPT in the plasma $\mathrm{pH}$ (neutral $\mathrm{pH}$ ) and association with the human serum albumin shifts the equilibrium producing the water soluble E ring opened carboxylate form which is less potent than the lactone form [66]. Drug resistance in cancer cells may be due to overexpression of MDR, reduced levels of topo I, long cell cycle time, drug resistant mutant topoisomerase and altered DNA repair function [67]. Restriction of the use of CPT has led to the development of various analogues of CPT.

\section{Currently available techniques:}

In particular, there is a pressing need for a high throughput screening platform to identify new topo I drugs and characterize the nature of the drug action (IFP versus CIC). While some 
methods exist that can achieve this goal (i.e., agarose gel electrophoresis, SDS-K ${ }^{+}$, ICE Bioassay) [68-70], such methods are not readily HTS adaptable and are not easily scalable. Several new assays have been proposed to improve our ability to find new topoisomerase active agents, such as the triplex formation assays, dual color fluorescence spectroscopy and Surface Plasmon Resonance approaches; however, these methods are technically complex and often laborious or indirect assays [71-73]. Widespread use of these techniques has been hampered by these rate limiting aspects. We report a very simple method for HTS to identify topo I targeting agents. The technique involves the binding of His-tagged topo I protein to microtiter plates under conditions that preserve enzyme activity. DNA substrate is added and a sensitive DNA dye is used to monitor retention. Reconstruction experiments reveal that topo poisons yield an elevated fluorescent readout, while catalytic inhibitors yield a repressed fluorescent signature relative. The method represents a dual readout that not only identifies topo I targeting agents, but also provides rapid insight on possible mechanisms. 


\section{CHAPTER TWO: MATERIALS AND METHODS}

\section{Materials}

Anti-topoisomerase I monoclonal and polyclonal antibodies were provided by TopoGEN, Inc. (Port Orange, FL). Supercoiled plasmid DNA containing the high affinity topo I hexadecameric recognition sequence (pHOT1) was from TopoGEN. The test compounds were provided by the Developmental Therapeutics Program from the National Cancer Institute as a plated diversity set, mechanistic set and approved oncology drug set. The nickel coated 96 well plates were from Fisher Thermoscientific. Nickel-NTA agarose affinity beads were from Qiagen and Picogreen was obtained from InVitrogen.

\section{Purification of human topoisomerase I}

Topo I was overexpressed as a His-tagged protein in Baculovirus. Experiments were performed with wild type (wt) and mutant (Y723F) proteins from commercial sources (kindly provided by TopoGEN, Inc., Port Orange, FL). Results were repeated with topo I purified as described by Stewart and Champoux [74]. Active fractions were supplemented with $50 \mu \mathrm{g} / \mathrm{ml}$ BSA prior to dialysis (enzyme purity was greater than $98 \%$ and was stored at $4^{\circ} \mathrm{C}$ for up to 6 months without loss of activity). The purified fraction was free of topo II as determined by kDNA decatenation analyses and Western blot probing using anti-topo II polyclonal antibody (TopoGEN, Inc.). The final fraction was nuclease free based on incubation of pHOT1 with excess (>500 units) of topo $\mathrm{I}$ in the presence of $5 \mathrm{mM} \mathrm{MgCl}_{2}$. One unit of topo I will relax approximately $50 \%$ of pHOT substrate $\left(100 \mathrm{ng}\right.$ input) in $30 \mathrm{~min}$ at $37^{\circ} \mathrm{C}$. The final specific 
activity of a typical preparation ranged between 0.5 to $5.0 \times 10^{6}$ units per $\mathrm{mg}$ of protein (total yield of 2-2.5 mg).

\section{Plasmid relaxation and cleavage assays}

Topo I was assayed by relaxation of pHOT1 supercoiled DNA (form I). Reactions were carried out in TGS buffer (10mM Tris $\mathrm{HCl}$ (pH8.0), 1mM EDTA, 150mM NaCl, 5\% glycerol, 0.1\% BSA and 0.1mM spermidine) and $100 \mathrm{ng}$ (or $200 \mathrm{ng}$, where indicated) form I pHOT1 DNA for $30 \mathrm{~min}$ at $37^{\circ} \mathrm{C}$, terminated with $5 \mathrm{uL}$ of stop buffer ( $5 \%$ sarkosyl, $0.125 \%$ bromophenol blue, $25 \%$ glycerol) and loaded onto a $1 \%$ agarose gel. The gels were run at $1.5-2 \mathrm{~V} / \mathrm{cm}$ until the dye front was $75 \%$ down the gel, followed by staining for $30 \mathrm{~min}$ with $0.5 \mu \mathrm{g} / \mathrm{mL}$ ethidium bromide (EB), destaining for 10 min in water and digital imaging using a Gel Doc system (Syngene). Cleavage reactions were performed as above in TGS buffer and after incubation at $37^{\circ} \mathrm{C}$ for 30 min, they were terminated with SDS (1\% vol/vol final) followed by digestion with $0.5 \mu \mathrm{g} / \mathrm{mL}$ proteinase K (30 min $56^{\circ} \mathrm{C}$ ). The DNA was extracted by Phenol:Chloroform precipitation, and following addition of $3 \mathrm{M}$ sodium acetate, $\mathrm{pH} 5.2(0.1 \mathrm{vol}), 2 \mu \mathrm{L}$ of $20 \mathrm{mg} / \mathrm{mL}$ glycogen, the DNA was ethanol precipitated. The pellet was washed with $100 \mu \mathrm{L}$ of $70 \%$ cold ethanol, air dried and then dissolved in $20 \mu \mathrm{L}$ of $\mathrm{TE}(10 \mathrm{mM}$ Tris- $\mathrm{HCl}, \mathrm{pH} 7.5,1 \mathrm{mM}$ EDTA) prior to electrophoresis in $1 \%$ agarose gels containing $0.5 \mu \mathrm{g} / \mathrm{mL}$ ethidium bromide (gel and running buffer). Gels were destained in water for 10 min prior to photo documentation. 


\section{Solid phase assays}

A fixed number of topo I units (50 $\mu \mathrm{L}$ final volume) were bound to nickel coated, 96 well plates for $2 \mathrm{~h}$ at room temperature. All plates are freshly prepared and used the same day; however, the enzyme bound plates can be stored at $4^{\circ} \mathrm{C}$ for $48 \mathrm{hr}$ prior to use. The unbound enzyme was removed by aspirating off the initial binding solution followed by three washes (200 $\mu \mathrm{L}$ each) with cold PBS containing $0.05 \%$ Tween-20 (PBS-T). These conditions effectively remove all unbound topo I (Figure $2 \mathrm{~S}$ ). Topo I reactions were initiated by addition of a pre-mix solution of TGS and $100 \mathrm{ng}$ of Form I pHOT1 DNA in the presence or absence of test or control drugs. Note that supercoiled (Form I) DNA substrate is ideal for screening CIC while linearized pHOT1 DNA is ideal for IFP screens; however, both CIC and IFP can be detected using the Form I DNA substrate albeit with less resolving power (see Fig.3S). Drugs were dissolved in DMSO and the final DMSO concentration in the reaction never exceeded $1 \%$ (assays tolerate up to $1 \%$ DMSO, however solvent controls should be included). Reactions were incubated for $1 \mathrm{hr}$ at $37^{\circ} \mathrm{C}$ and terminated by the addition of 0.1 vol of $1 \%$ SDS (vol:vol) followed by a 5 min incubation at $37^{\circ} \mathrm{C}$. The reaction mixture was next aspirated and washed three times with $200 \mu \mathrm{L}$ PBS-T. Picogreen $(100 \mu \mathrm{g} / \mathrm{mL})$ was diluted in TE (1:400) and $200 \mu \mathrm{l}$ was added to each well followed by incubation in the dark for $5 \mathrm{~min}$. The relative fluorescence was measured at $485 \mathrm{~nm}$ excitation and 525nm emission wavelength using a Tecan Ultra plate reader (Tecan, US, Durham, NC). 


\section{Data and statistical analysis}

Z' factor analyses were performed to determine dynamic range and variability of the topo I HTS [75]. Z' values should exceed 0.5 for a functional and robust HTS assay based on

$$
Z=1-\frac{3 *(\text { standard deviation of CPT wells }+ \text { standard deviation of no drug wells })}{[\text { Average of CPT }- \text { Average of no drug }]}
$$

HTS experiments were conducted and the data analyzed from 10 different experiments performed on different days with different operators and using different inputs of topo I as well as different lots of enzyme and CPT. The drugs were diluted to a single concentration and HTS assay was done. The raw absorbance values were used to calculate \% inhibition using the formulas 2, 3 .

$\%$ inhibition for IFPs $=100 *\left[1-\left(\frac{\text { no drug }}{\text { drug }}\right)\right]$

$\%$ inhibition for CICs $=100 *\left[1-\left(\frac{\text { drug }}{\text { nodrug }}\right)\right]$

Drugs showing $>50 \%$ inhibition were selected and further characterized by repeating the assay in triplicates. Statistical significance between groups was determined using Student's t test (twotailed) using GraphPad Prism version 5.0. 


\section{CHAPTER THREE: RESULTS}

\section{Immobilization of Topo I on Beads or Solid Phase and Activity Recovery}

His tagged topo I was affinity purified [74] and we consistently obtained high yields of intact topo I (mg) with total activity levels typically well over two million units at over 1500 units/ul (Fig 4). The purified enzyme was capable of detecting topo I cleavage products both in the presence and absence of CPT (Fig. 4 and Fig. 9). The enzyme was bound to a nickel affinity beads (with a heterologous protein (bovine serum albumin) as a negative control) and assayed for enzymatic activity. The data show that bead bound topo I retained excellent CPT mediated DNA cleavage activity compared to solution-based reactions with a $20-30 \%$ reduction in overall efficiency (Fig. 5). To investigate topo I activity on a solid surface, the enzyme was bound to nickel coated microtiter plates. Reconstruction experiments on washing conditions establish that even with very high (>2000 units) input topo I, three washes were sufficient to remove unbound topo I and reduce activity to undetectable levels in the last wash (not shown but see Fig. 5). We next used the same lot of enzyme and put equivalent amounts of activity in the wells followed by addition of supercoiled DNA to assay topo I relaxation activity of the bound enzyme. Enzyme titrations were compared with liquid assays to determine the amount of topo I protein required to relax $50 \%$ of the Form I DNA substrate. The data reveal that in liquid phase (conventional topo I relaxations) ca. $7 \mathrm{ng}$ of enzyme relaxes half of the substrate. In solid phase reactions (where topo I was bound, free enzyme washed out, followed by addition of Form I DNA to the wells) ca. 3036 ng of enzyme would relax $50 \%$ of the substrate (Fig. 6A). We suspect that most of the loss may be due to fixing the enzyme to a solid surface which either affects controlled rotational events [43] or limits diffusion rates and the ability to engage the DNA in a three dimensional 
search. The latter prospect seems likely since we did not see large activity losses when binding topo I to an affinity bead (Fig. 5) which is free to move through the solution reaction. The loss of enzyme activity is offset by the relatively high yields of enzyme; therefore, it is not a ratelimiting step in HTS operations in this system. To address this point, we next determined how much enzyme each well could accommodate at saturation. The wells were hydrated using a solution of PBS-T (PBS with and $0.05 \%$ Tween) producing stringent conditions for specific binding (however, these conditions are compatible with topo I activity, not shown). Different concentrations of enzyme were diluted into $50 \mu \mathrm{l}$ of PBS-T and added to each well followed by incubation for $2 \mathrm{~h}$ at room temperature with mild shaking. Topo I binding was confirmed by ELISA using a mouse monoclonal primary antibody specific for topo I (Fig. 6B). Maximum protein binding was detected with $256-1024$ units corresponding to 0.25 to 0.5 ug of input topo I. These values are very close to the theoretical maximum of binding capacity of the wells, based on information from the commercial supplier of the plates. To more accurately assess saturation binding, we eluted topo I (with imidazole) and analyzed the recovered protein by Western slot blotting (which gives good linearity with higher concentrations of antigen). Based on slot blots, the binding capacity is actually closer to $1.5 \mu \mathrm{g}$ of enzyme (data not shown). This result suggests that each well can accommodate large amounts of topo I and despite the loss of activity; we can bind sufficient amounts of enzyme to over-ride this limitation.

\section{Topo I Cleavages in the Absence of CPT.}

Nicked cleavage products accumulate even in the absence of CPT (Fig. 7). At a threshold level of about 100 units of input topo I, cleavage products can be seen in liquid assay. The 
amount of form II cleavage product did not significantly increase even at much higher ratios of enzyme:DNA (up to 600 units of topo I) and the cleavages reached a stoichiometric maximum at 100 units. That the cleavage product was due to topo I and not a contaminating nuclease can be ruled out since the nicked plasmid DNA was not detected unless proteinase K digestions were carried out (data not shown). This result clearly demonstrates that topo I cleavage complexes form in the absence of CPT, especially at high input levels of enzyme. Moreover, the cleavage reactions are not saturated since only a small fraction of input pHOT1 DNA (less than 20\%) was converted to form II product (Fig. 7, histogram). This should facilitate detection of poisons by the method.

\section{Detection of CPT Mediated Cleavage Complexes in the Solid Phase Assay}

Next, we titrated topo I in the presence and absence of the prototypic IFP, CPT. At low enzyme inputs signals were low as expected; however, at all concentrations tested, the fluorescent signature was increased by CPT (Fig. 8A). Note that CPT stimulation increased with more input topo I; thus, between 16-64 units, CPT resulted in 1.2-2 fold increases in DNA binding to wells, while reactions containing >100 units gave 2.5-2.7 fold increases. This behavior is consistent with the conventional liquid assays (i.e., detecting cleavages is optimal at high ratios of topo:DNA). To demonstrate that CPT stimulation was correlated with topo I activity, we prepared a catalytically inactive mutant (Y723F) that can bind DNA (but cannot initiate cleavages). The mutant protein did not display any CPT stimulation at the highest input of protein (Fig. 8B); however, DNA binding (relative fluorescence) was detected with mutant topo I, as expected (data not shown). We also analyzed DNA retained in wells (after reaction 
termination) by digesting with proteinase $\mathrm{K}$ to release the DNA, followed by agarose gel electrophoresis to resolve relaxed and nicked open circular forms. In the absence of CPT (Fig. $8 \mathrm{~A}, 512$ units) $20 \%$ of the DNA that was bound to wells was form II (and $80 \% \mathrm{I}^{\mathrm{r}}$ ). In CPT reactions, form II DNA increased to $70 \%\left(30 \% \mathrm{I}^{\mathrm{r}}\right)$. Based on these results, the solid phase assay can detect interfacial poisons. Additional controls verify that the assay requires on presence of all reactants. CPT alone or DNA alone (Fig. 8C) gave background signals. Similarly, adding CPT to topo I without input DNA gave background fluorescence. Picogreen signals (Fig. 8C) depend on both topo I and DNA. As expected, CPT addition yielded the highest picogreen signal in the topo I and DNA wells. As shown in Fig. 8D, the signal is lost when the wells are digested with DNase I; however, a small background remains in CPT reactions (topo I partially blocks access of the nuclease in the covalent complex) [76].

\section{Termination, Optimization and Dose Dependence of Solid Phase Reactions}

Termination and washing conditions of the solid phase reactions were examined next. SDS reduced the CPT complexes (10-30\% without affecting the non-CPT residuals) and the impact of this SDS decrease was nearly identical from 0.1 to $1 \%$ (Fig. 9A). SDS in this range does not disrupt the nickel-His affinity complexes [77] and we confirmed that topo I is not being released from the plates under these conditions (data not shown). From this result we conclude that SDS reduces CPT based signals but has little if any affect on non-CPT reactions. The influence of elevated CPT concentrations was also evaluated; however, neither the solid phase nor liquid phase reactions displayed drug concentration dependency over the range tested (Fig. 9B). Since appearance of form II DNA is a single hit phenomenon, high enzyme:DNA ratios 
(100:1 as used here) favor efficient formation of the nicked cleavage product, even at relatively low levels of CPT (down to $1 \mu \mathrm{M}$ ); however, reducing input topo I levels and titrating lower concentrations of CPT (below $1 \mu \mathrm{M}$ ), we observed the expected CPT dose response that closely matched gel based cleavage data (Fig. 9C). We also evaluated different termination and washing procedures to develop some understanding of the nature of DNA retention once the input plasmid engages the attached topo I (Table 2). Chaotropic agents had no affect on DNA retention either in the presence or absence of CPT. Increasing the volume of the binding/reaction in a 96 well plate format reduces the fluorescent signal somewhat, probably because surface areas increase to a larger extent over volume, thereby decreasing the probably of productive topo I/DNA interactions, as noted above. Elevated salt in washing buffers tends to release some of the bound DNA (but not all) and even very high $\mathrm{NaCl}$ levels (1M-2M) do not release the DNA once it is bound.

\section{Heat Denatured Topo I is Inactive in Solid Phase Assays.}

Heat denatured topo I bound efficiently to the wells based on ELISA (as in Fig. 8, not shown) despite being catalytically inactive (see inset gel Fig. 10A). We then measured DNA retention in CPT and non-CPT reactions containing identical dilutions of the enzyme (Fig. 10A). The data clearly show that CPT stimulation requires catalytically active topo I (more noticeably at the higher inputs of topo I). In the absence of CPT, significant increases in DNA retention of native over denatured enzyme were seen, again at the higher inputs of topo I (at 128 and 512 units, Fig. 10A). Retention of denatured topo I in the absence of CPT was close to background levels (reactions lacking topo I). 


\section{Reconstruction and optimization of topo I HTS to detect IFP.}

From the 'approved oncology drugs set' available from NCI (Developmental Therapeutics Program), we selected 8 compounds at random for reconstruction testing of the solid phase HTS Assay.These agents were tested at a relatively high concentration $(100 \mu \mathrm{M})$ in order to assess whether the assay is influenced by non-specific events. The tested drugs range from DNA hypomehtylating agents (Azacitidine, Decitabine), a tyrosine kinase inhibitor (Erlotinib), a topo II catalytic inhibitor and radio-chemoprotective agent (Amifostine), an immune response modifier (Imiquimod), a bifunctional alkylator (Melphalan) and a bisphonic acid that inhibits bone resorption (Zoledronic acid). All of these agents inhibit cell growth with $\mathrm{IC}_{50}$ values in the low micromolar range and except for Amifostine are non-topo targeting agents. None of the agents would be scored as either IFPs based on solid phase HTS. As confirmation, none of the compounds induces topo I cleavage activity (see inset gel, Fig. 10B). We next asked whether it was possible to increase the IFP Ratio signal to noise ratio (defined as + drug readout/no drug control), which typically ranges from 2 to 2.7 fold (Fig. 10A). We found that using higher inputs of linearized plasmid, significantly improved the IFP Ratio (Fig. 10C) to as much as 6 fold. In contrast, Form I DNA was less ideal since the supercoiled DNA tends raise the background of DNA cleavage with higher inputs of substrate (Fig. 10D).

\section{Reconstruction and optimization of topo I HTS to detect CIC.}

In order to optimize the assay for detecting CIC effectors (drugs that block topo I binding or catalytic activity), we screened over 90 compounds from the approved oncology set and identified two potent CIC drugs (mitoxantrone and daunorubicin) both of which are DNA 
intercalators (Table 3). To optimize detection of CICs we used mitoxantrone (MTX) as a prototypic CIC. As shown in Fig. 11A and 11B, increasing inputs of linear and Form I DNA confirm that $100 \mathrm{ng}$ of supercoiled substrate performed optimally and gave the highest CIC Ratio (no drug/+ drug ratio). In this case, CIC Ratios were in the 4-6 fold range. The CIC Ratio also depends on the amount of input topo I and the ratio can be as high as 10-12 fold (Table 3). Therefore, supercoiled DNA is the preferred substrate for CIC detection while linear plasmid works best for IFP. As shown in Fig. 11C, the CIC ratio is proportional to input MTX concentration under these conditions (using Form I DNA). Fig. 11C shows, for comparison, a dose response with CPT using linear DNA, which increases the signal readout with IFPs (see Fig 10C). Again, we obtained excellent drug response in the optimized format with linear DNA.

\section{Detecting CIC and IFP.}

To identify CIC and IFP and utilize the solid phase method as a gating assay, we performed solid phase screens using known structures (courtesy of NCI Division of Therapeutics) at a single concentration with the optimized assay (CIC screens used Form I DNA and IFP screens used linear plasmid). Drugs that showed above 50\% inhibition were tested in triplicates and their $\mathrm{p}$ values were calculated. Statistical cut offs based on p values (Table 3) show the positives we detected for each mechanistic class. In the CIC screens, known compounds were evaluated at a single concentration $(10 \mathrm{uM})$. The positive control (mitoxantrone) was a strong positive that met the statistical cut off $(\mathrm{p}<0.01)$ and showed strong inhibition of topo I relaxation with gel based assays. Another DNA intercalator (daunorubicin) was identified which is less active than the prototype mitoxantrone and DNA intercalators are 
known to inhibit topoisomerases [78]. The other natural products (compounds 2-7, Table 3) scored as potential effectors of topo I catalytic activity with variable levels of potency and all under the cutoff value for significance. None of these compounds displayed catalytic inhibition using plasmid DNA. Analysis of IFP active agents reveals mostly topo I poisons as expected (compounds 8-10); however, the IFP screen also detected estrogen receptor modulators (Tamoxifen, Ralaxofene) [79] and several DNA alkylating agents (Procarbazine, Nitrogen/Uracil mustards).

\section{Z' Determinations}

A useful parameter to assess signal dynamic range as well as control variations is the $Z$ ' factor. We determined Z' values for our data for assays that display maximal differences between positives (+CPT) and negative drug controls. For example, with higher inputs (1024 and 512 units, Fig. 3A) the +CPT mean was $2877(\mathrm{SD}+/-153)$ and in $-\mathrm{CPT}$ the mean value was 1181 (SD +/- 44.5) yielding a Z' value of 0.808. These data were derived from multiple experiments performed on different days using different lots of enzyme and with different operators. Thus, the solid phase method is robust in detecting IFP active agents like CPT ( $Z$ ' values in excess of 0.5 are considered acceptable) We note however that Z' values were strongly dependent on topo I inputs, as expected, since the differences between positive and negative controls was much less obvious below a certain threshold of input enzyme. Experiments with low input topo:DNA ratios yielded a lower CPT stimulation index (see Fig. 8A, 16-64 units); however Z' values were still greater than 0.5 (actual values ranged from 0.57 to 0.58 ). We obtained similar Z' values (0.60.8) using MTX and a CIC based assay screen (not shown). 


\section{CHAPTER FOUR: DISCUSSION}

TopoisomerasesI are ubiquitinous enzymes that play an essential role in various cellular processes related to DNA metabolism and has been the target for various anticancer and antimicrobial agents. However lack of a simple and efficient processes has impeded the rapid detection of inhibitors of topoI. We have developed a simple high throughput screening method that facilitates the detection and differentiation of drugs that form complex with topoI and drugs that inhibit the catalytic activity of topo I.

We have made use of the baculovirus expression system to produce very high yields of His tagged topo I. The conventional liquid phase assay has been modified here by tethering of the His tagged topo I to the Ni coated plate making it a solid phase assay. Binding of the topo I to the plate was confirmed by ELISA which showed maximum binding at $0.25-0.5 \mu \mathrm{g}$ of topo I. The bound enzyme was then eluted by immidazole and detected by western blotting showing the the stability of the immobilized enzyme. We can rule out the possibility of degradation or desoption topoI bound to the wells as the proteins remained intact. The supercoiled DNA incubated with the bound DNA was found to be relaxed showing that the enzyme remained catalytically active. However efficiency of the enzyme activity was found to be reduced which was due to the immobilization of the enzyme. Topo I is a highly dynamic enzyme that scans along the DNA molecule binding to the nodes. Pinning down the enzyme has probably restricted the three dimensional interaction of the enzyme with the DNA substrate. The reduced activity is not because of the chemistry of His-Ni as the bead bound enzyme was found to be more active due to the free mobility and surface interaction with the substrate DNA molecules. The assay is well 
suited for HTS operation as a single enzyme purification can yield sufficient amount of topo I to screen 10000 to 15000 compounds with 250U / well.

The assay could be summarized as binding of the topoI to the plates followed by addition of the DNA substrate and detecting the DNA bound to the topoI using picogreen dyes. The fluorescence signal results from relaxed and nicked open circular products of topo I. However elevated signals were obtained when CPT was added to the reaction mixture. This was due to the trapping of the ternary complex by the drug. The magnitude of the signal increased with increasing concentration of topo $\mathrm{I}$ in the wells explaining that the cleavage requires stoichiometric amounts of topo I molecule. Thus in accordance with the 1:1 topo DNA ratio, increasing the amount of topoI increased the complex formed and hence the signal. The signal thus obtained is also mainly due to the complex formation by the active enzyme as it diminished when denatured or catalytically inactive enzyme was used in the assay.

However a small percentage of relaxed DNA was found in the plates in the absence of the drug. Suprisingly, the relaxed DNA is only partially released by high salt and 1\% SDS was less effective. The addition of proteinaseK or DNase totally eliminated this DNA, clearly indicating the topo I interaction with the DNA was responsible for the signal. Similarly use of a heat denatured topo I significantly reduced the signal indicating the enzyme activity was necessary for the retention of DNA. The interaction of the relaxed DNA to the bound topo I may be due to some unusually strong electrostatic or ionic bonding different from what is seen in the free solution and represents salt and detergent resistant clamping. Some plausible explanations may be as because of the multiple protein-DNA contacts as the topo I clamps surrounds the DNA. 
The relatively large quantities of topo I results in numerous such interactions resistant to salt release. Likewise, the immobilization may alter the diffusion dynamics that results in formation of unique topological structures tethered that cannot be easily washed away.

The metrics of this HTS was further optimized to screen for inhibitors and poisons, which uses different DNA substrates in the reaction mixture. In some cases, if the researcher is interested in screening for interfaction poisons, they may use the linear DNA or in the case of inhbitors they may use the supercoiled DNA which produces high signal to noise ratio. However the method also works with supercoiled DNA allowing one to potentially discriminate IFPs from CIC in a single screen. While IFP increases the fluorescence signal CIC decreases the readouts. CPT and MTX were used as the positive internal controls for the assay. This method serves as a gating system which could be used to identify positives and negatives at a single concentration. The hits identified here could be tested in triplicates to establish the statistical significance with the $\mathrm{p}$ values. The positive hits could further be verified by the conventional agarose gel electrophoresis.

The plate assay is amenable to do various titrations of the compounds and produce quatitative data comparable to the liquid phase assay. Thus is could serve as a rapid and robust system to screen compounds. In the current investigation a number of key points have to noted: First the assay could be used to characterisize both inhibitors and poisons. Second: the RFU values exhibit acceptable correlation with the liquid assay data Third: this could be applied to any other DNA transacting enzyme. 


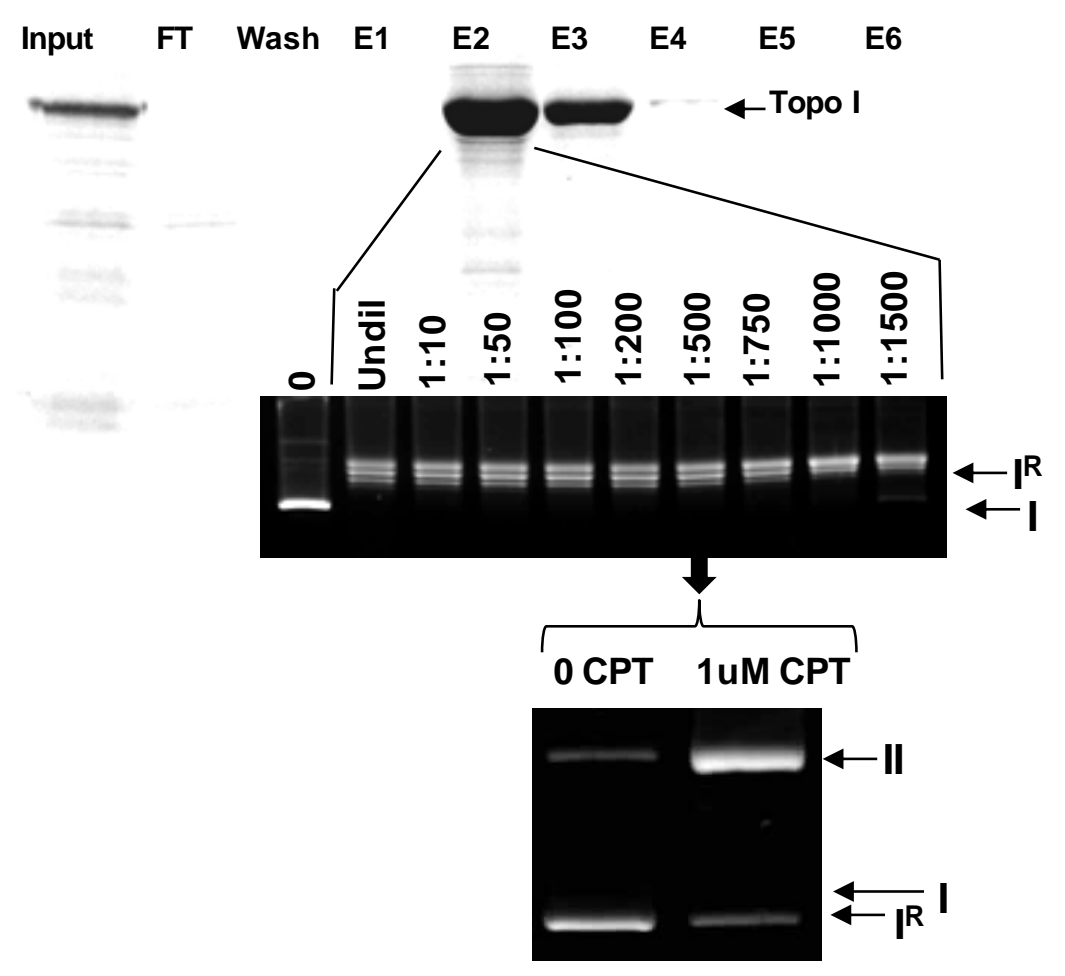

Figure 4: Purification of human topo I as a His tag product 


\section{Figure 4: Purification of human topo I as a His tag product}

Baculovirus infected SF-9 cells were harvested as described in "Materials and Methods" and the crude extract loaded onto the nickel column. Input, FT (flow through, column void), wash fractions are indicated. The imidazole eluted fractions (E1-E6) are marked. The E2 fraction contained $2.24 \mathrm{mg}$ of topo I, corresponding to a $22 \mathrm{uM}$ yield with over $2 \times 10^{6}$ units of enzyme. This fraction was diluted from 0 to 1:1500 and assayed for relaxation of plasmid DNA (upper gel image). Cleavage activity of His-tag topo I was assessed in the lower gel. Purified topo I (500 units) was incubated with zero or $1 \mu \mathrm{M}$ CPT and $100 \mathrm{ng}$ of pHOT1 supercoiled DNA for 30 min at $37^{\circ} \mathrm{C}$ and reactions terminated with $1 \% \mathrm{SDS}$. After proteinase $\mathrm{K}$ digestion, samples were loaded directly onto a $1 \%$ agarose gel containing $0.5 \mu \mathrm{g} / \mathrm{mL}$ ethidium bromide. The positions of

supercoiled (form I), relaxed (form $\mathrm{I}^{\mathrm{R}}$ ) and nicked open circular (form II) DNAs are indicated. Low levels of topo I cleavage products are visible in the minus drug control. 

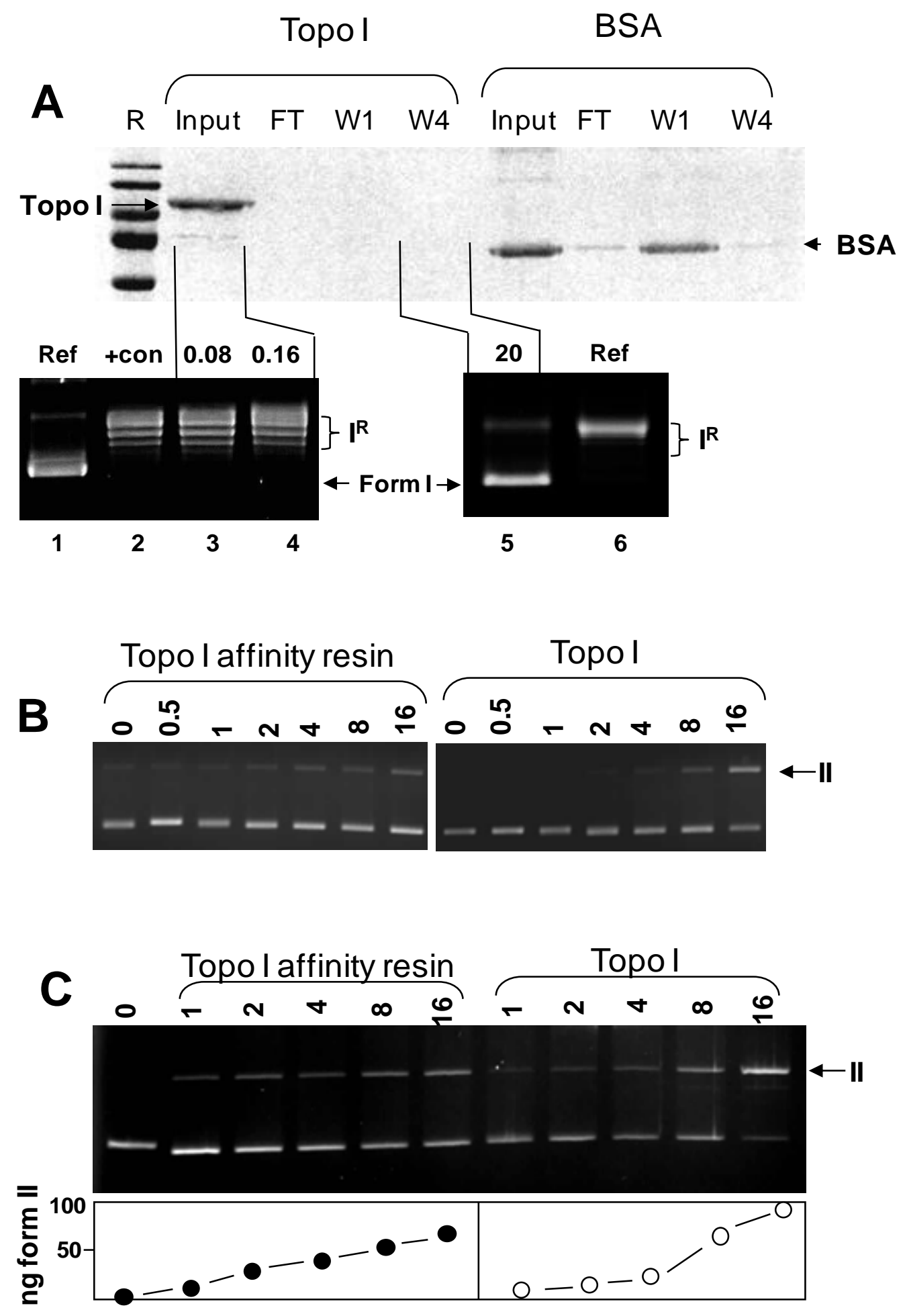

Figure 5: Topo I activity on affinity beads 
Figure 5: Topo I activity on affinity beads.

(A) Nickel sepharose beads were incubated with purified His-tag topo I or BSA. Input proteins and FT (flow through) fractions are marked. The beads were washed by centrifugation (10 bead volumes per wash) and each wash fraction collected and loaded onto an SDS-PAGE for analysis by staining with coomassie blue. Below the input lane is a topo I relaxation assay of affinity beads that were washed to remove unbound enzyme. Lanes 1 and 2 contain a supercoiled DNA reference marker and topo I control, respectively. Lanes 3 and 4 are dilutions of washed beads (diluted to give 0.08 or $0.16 \mu \mathrm{L}$ as indicated) in PBS (20 $\mu \mathrm{L}$ reaction volume) to which $200 \mathrm{ng}$ pHOT1 supercoiled DNA was added directly, followed by 30 min incubation at $37^{\circ} \mathrm{C}$. DNA was recovered by proteinase $\mathrm{K}$ digestion and analyzed on a $1 \%$ agarose gel. Lane 5 is $20 \mu \mathrm{L}$ of W4 ( $4^{\text {th }}$ wash off the column) mixed directly with $200 \mathrm{ng}$ of pHOT1 supercoiled DNA and incubated as above (lane 6 is a relaxed DNA marker). (B) Cleavage Activity on Beads. Purified topo I cleavages were assayed in free solution form or on beads using $100 \mathrm{ng}$ pHOT1 supercoiled DNA. The indicated units of topo I were from the washed beads in Panel A (the number of input units of topo I input for the two assay sets were normalized based on relaxation activity.) Proteinase K was used to release DNA for gel analysis. Both solution and bead assays contained $10 \mu \mathrm{M}$ CPT added. (C) Cleavage Activity of Bead Bound and Free topo I. Equivalent amounts of topo I activity were titrated on beads (left) or as free enzyme (right) in cleavage reactions containing $10 \mu \mathrm{M}$ CPT. The position of nicked open circular (II) DNA is indicated. The plot below shows the digitized data from the gel. 


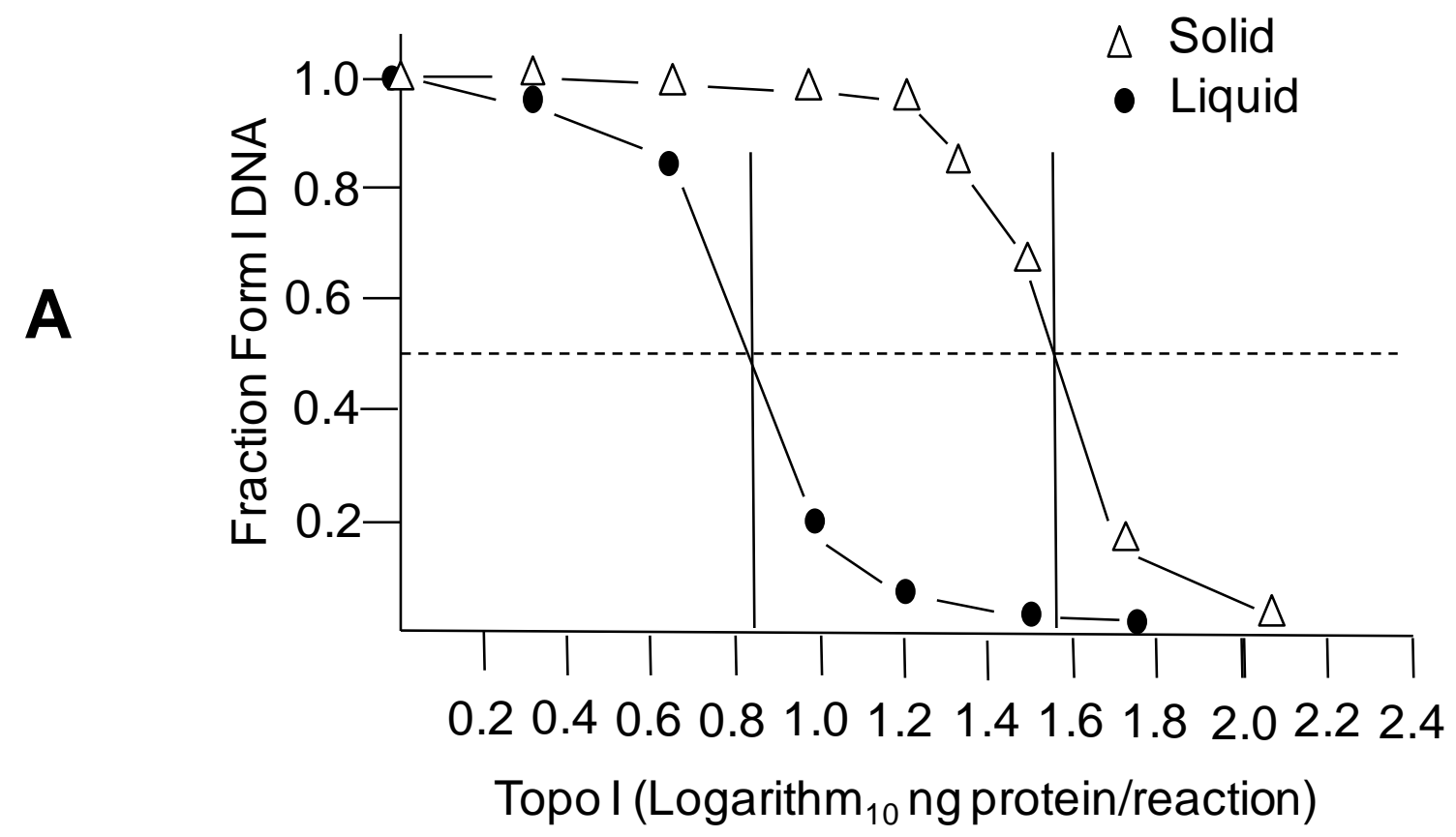

B

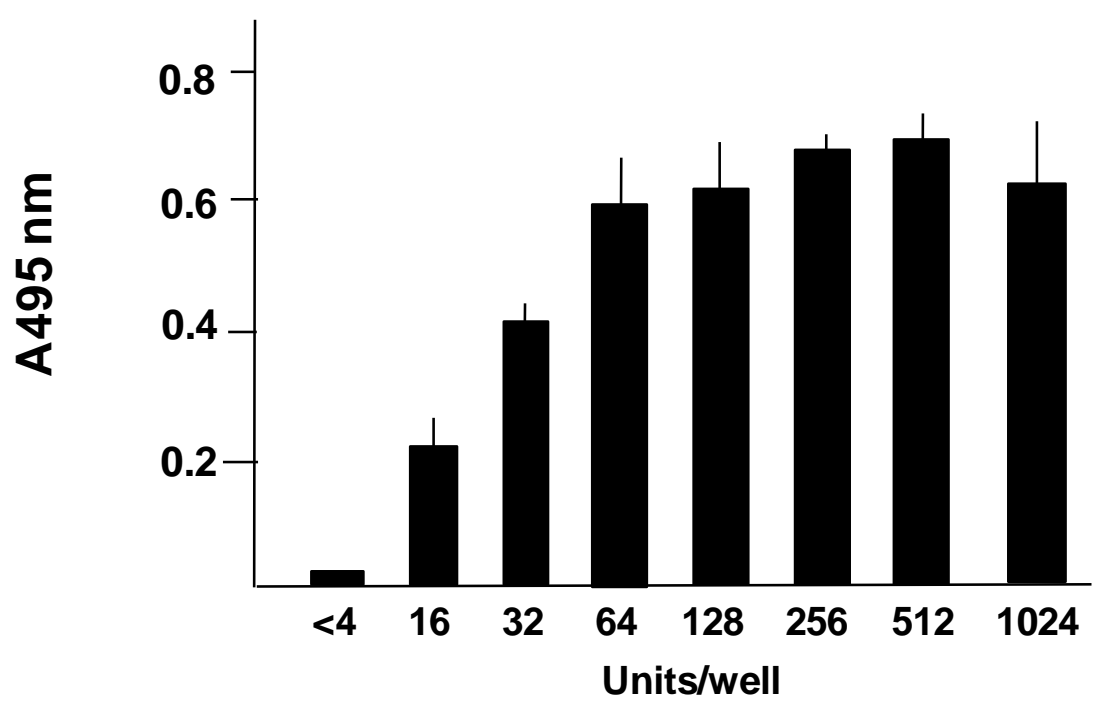

Figure 6: Analysis of Solid Phase and Liquid Phase Topo I Activity. 
Figure 6: Analysis of Solid Phase and Liquid Phase Topo I Activity.

(A) Topo I activity recovery in solid and liquid phase. Topo I titrations were carried out in liquid phase by conventional relaxation assays using $100 \mathrm{ng}$ of pHOT1 DNA. The solid phase assays were performed by binding the indicated amount of purified topo I protein to plates followed by sufficient washing to remove unbound enzyme. Reactions were carried out in the wells by adding $100 \mathrm{ng}$ pHOT1 in assay buffer and after incubation, proteinase K (plus $0.1 \%$ SDS final volume) was added and incubation continued for $15 \mathrm{~min}$ at $37^{\circ} \mathrm{C}$. The recovered DNA was then loaded onto an agarose gel to resolve supercoiled (form I) and relaxed DNA (form $\mathrm{I}^{\mathrm{R}}$ ). The gel data were digitized using a gel documentation system and software (Syngene).

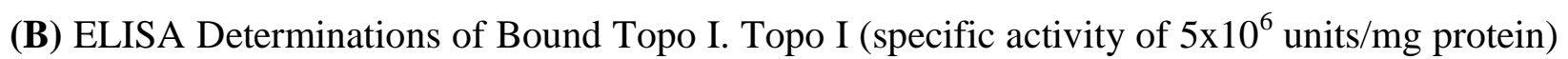
was bound and plates washed to remove unbound enzyme. The remaining signal was detected using a monoclonal anti-topo I antibody. The primary antibody was diluted 1:1000 in PBS-T and $100 \mu \mathrm{L}$ added per well $(1 \mathrm{hr})$ and wells were washed three times with $200 \mu \mathrm{L}$ of PBS-T, followed by the enzyme conjugated secondary (rabbit anti-mouse) at 1:500 in PBS-T. Plates were washed three times again with PBS-T and quantified at 595nm using TMB Peroxidase EIA substrate kit (Bio-Rad). 


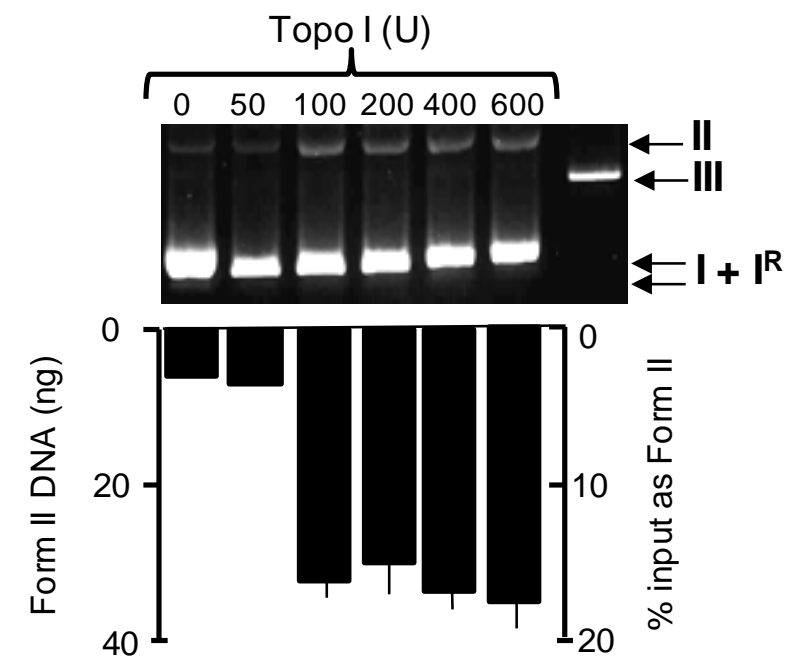

Figure 7: Topo I cleavages in the absence of CPT. 


\section{Figure 7: Topo I cleavages in the absence of CPT.}

Topo I reactions (liquid) were carried out at the indicated input of enzyme with $200 \mathrm{ng}$ of pHOT1 DNA. After termination with $1 \%$ SDS, the reactions were digested with proteinase $\mathrm{K}$ and loaded onto an ethidium bromide containing agarose gel. Positions of nicked open circular (II), linear (III) and relaxed $\left(\mathrm{I}^{\mathrm{R}}\right)$ plus supercoiled DNA (I) are indicated (the latter two forms comigrate in this gel system containing ethidium bromide). The amount of DNA in form II was quantified in each lane in the graph below the gel. 
A

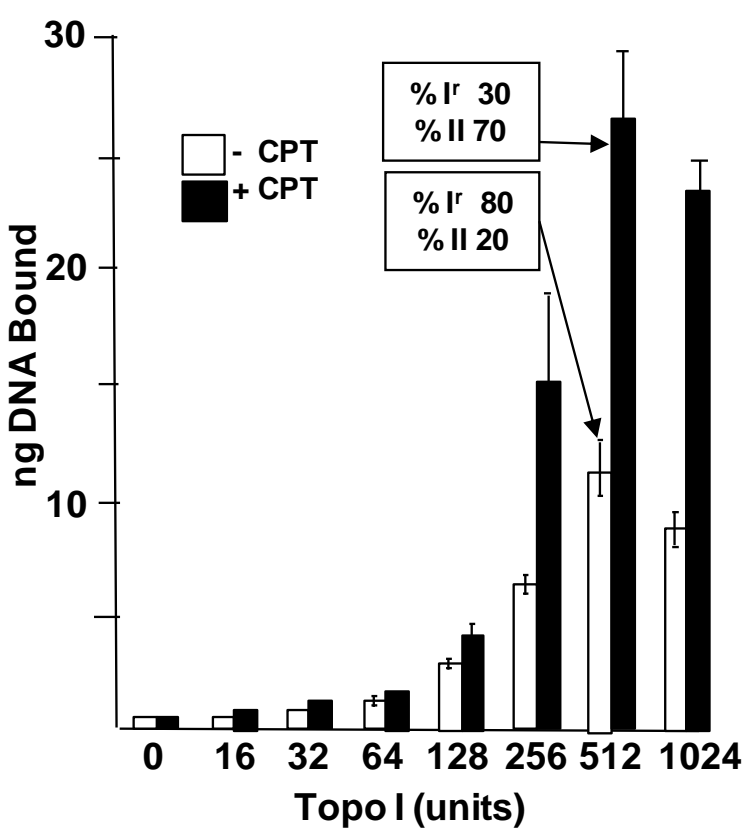

B

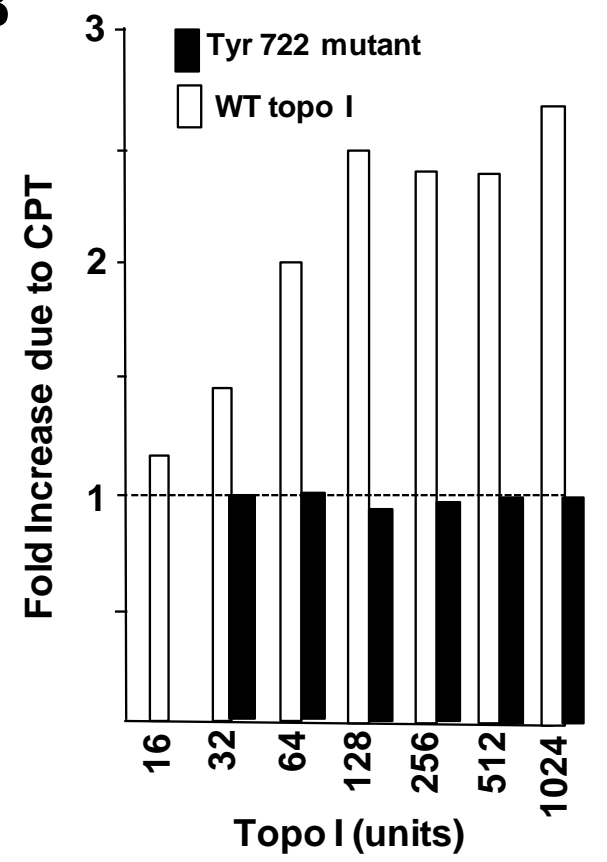

C $\quad 25007$
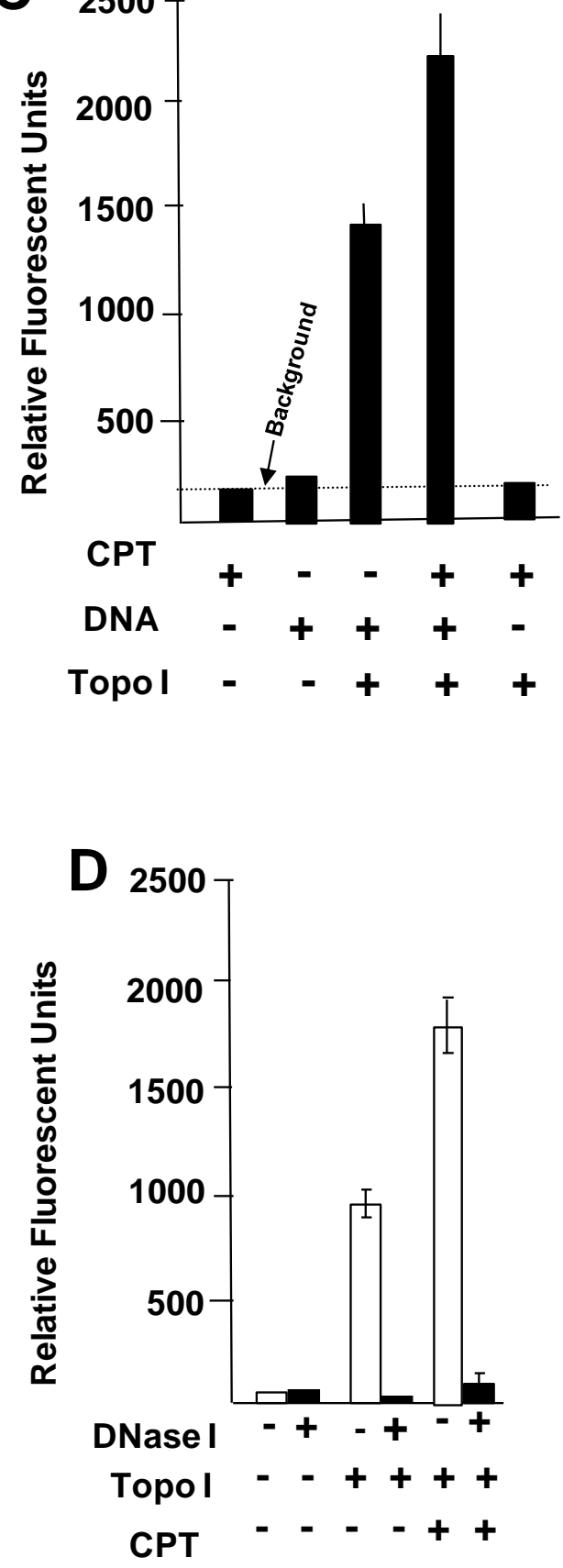

Figure 8: CPT Induced Cleavages in Solid Phase Assays 
Figure 8: CPT Induced Cleavages in Solid Phase Assay.

(A) Solid Phase Activity Titrations. Indicated amounts of topo I (based on liquid assays) were bound to Nickel plates in triplicate and reactions carried out in the absence or presence of $5 \mu \mathrm{M}$ CPT for $30 \mathrm{~min}$ at $37^{\circ} \mathrm{C}$ as indicated (100 ng Form I DNA input). In one set of reactions (512 units), the DNA was recovered and analyzed by gel electrophoresis to determine the fraction of relaxed or nicked open circular DNA. (B) Fold increase in DNA binding due to CPT. The data in the open boxes are based on results shown in Panel A to reflect changes in CPT stimulation over a range of input WT (wild type) topo I. The black shaded boxes are data from an equivalent titration (in terms of ng input protein) with Y723F topo I mutant that is catalytically inactive but can still bind DNA. (C) DNA binding depends on presence of both topo I and DNA. A series of reactions were carried out with the indicated solutes. CPT was added at $5 \mu \mathrm{M}$, DNA at $100 \mathrm{ng}$ and topo I at 512 units. Note that backgrounds (+CPT no DNA) were not subtracted (dashed line). (D) Bound DNA is released by DNase I digestion. The reactions were assembled with the indicated components (CPT added at $5 \mu \mathrm{M}$ ). DNase I was added at $50 \mu \mathrm{g} / \mathrm{mL}$ was added to the wells for $30 \mathrm{~min}$ at $37^{\circ} \mathrm{C}$ and the wells were washed with PBS-T three times (200 uL per wash). 

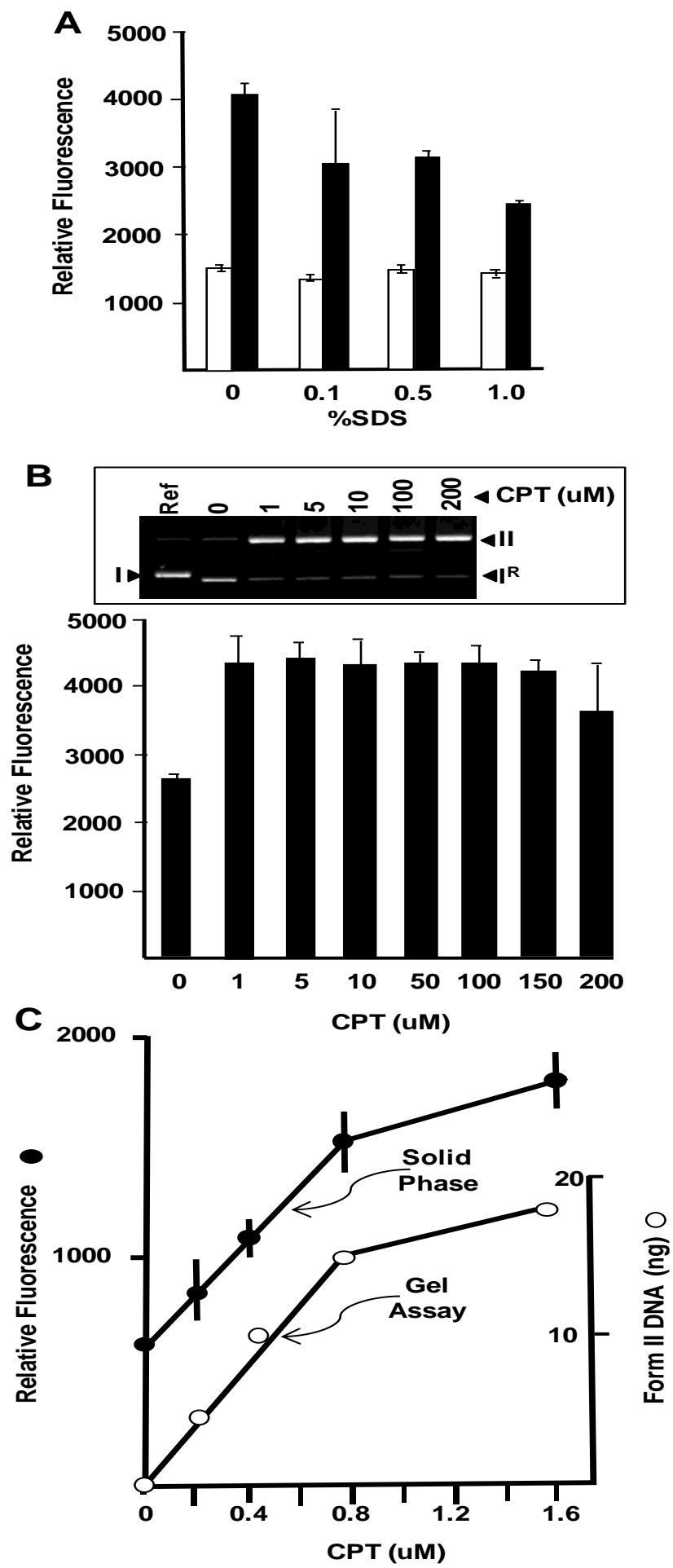

Figure 9: Reaction termination and CPT Titration Data. 


\section{Figure 9: Reaction termination and CPT Titration Data.}

(A) Effect of SDS in Termination Buffer. Minus (open bars) and plus (5 $\mu \mathrm{M})$ CPT (closed bars) reactions were terminated and washed with the indicated buffers that differ in SDS content. Reactions contained 512 units of topo I bound to plates. (B) High CPT Titration. Reactions contained 512 input units of topo I, $100 \mathrm{ng}$ of supercoiled (Form I) DNA and the indicated CPT concentrations. Identical reactions were processed in solution and the products analyzed by agarose gel electrophoresis with $0.5 \mu \mathrm{g}$ ethidium bromide/mL (C) Low CPT Titration. Solid phase reactions contained 256 units of topo I bound to wells plus the indicated amounts of CPT with $100 \mathrm{ng}$ of Form I input DNA (filled symbols). The same reactions were carried out in solution and nicked open circular DNA resolved by EB agarose gel electrophoresis (open symbols). 

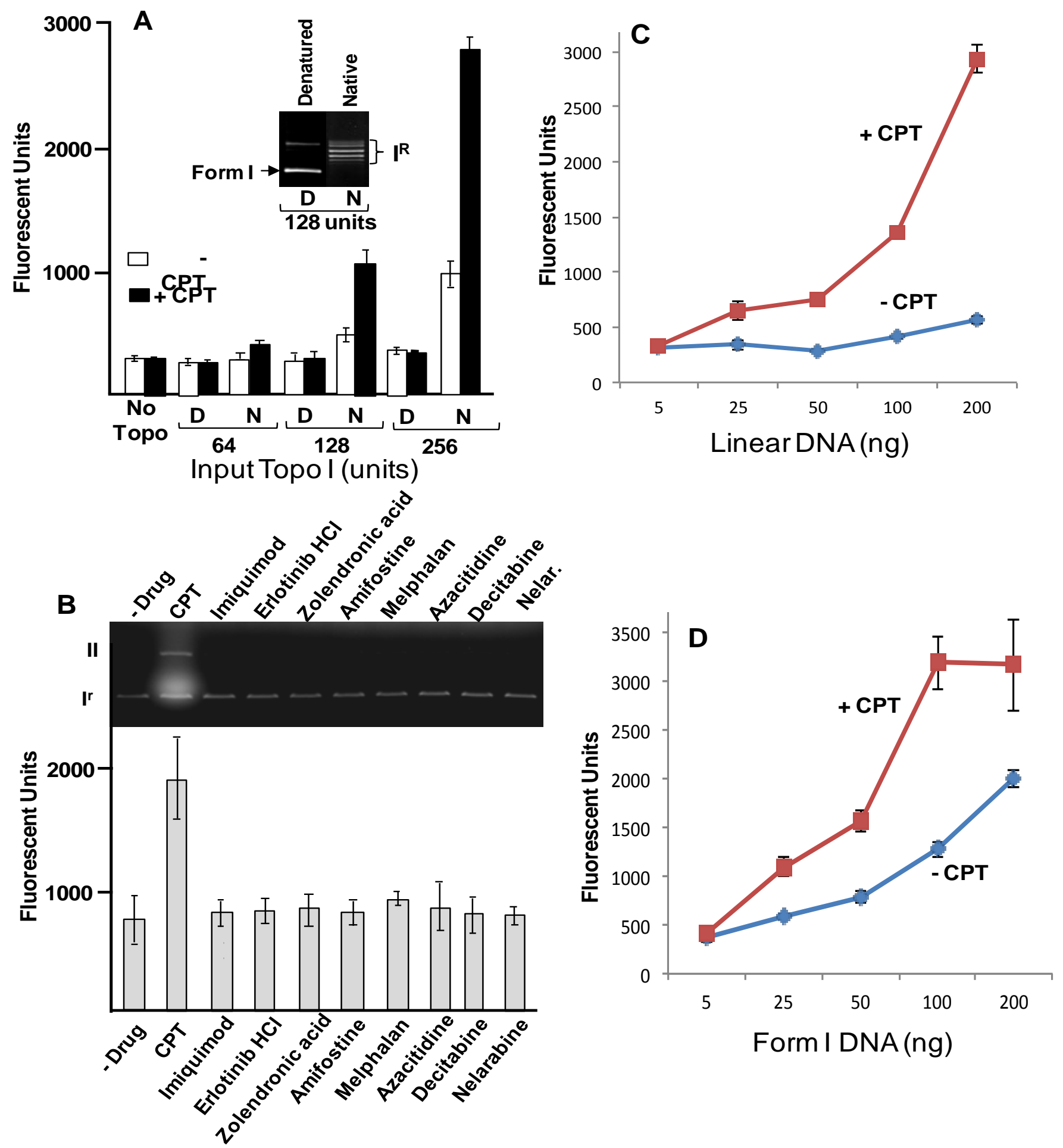

Figure 10: Native and denatured topo I and input DNA optimization. 
Figure 10: Native and denatured topo I and input DNA optimization.

(A) Native and Denatured Topo I Analysis. Purified topo I (512 units) was incubated on ice or at $95^{\circ} \mathrm{C}$ for $30 \mathrm{~min}$ and diluted with PBS. Each dilution was bound to nickel coated wells as described in "Materials and Methods" using the standard binding reaction (100 ng Form I DNA). Background signals (no topo input) are shown but were not subtracted. The inset agarose gel shows the activity associated with denatured and native enzyme. (B) Reconstruction Test Screens. Compounds were selected from the Diversity Set available from the NCI (see "Materials and Methods") and $100 \mu \mathrm{M}$ tested. Reactions contained 512 topo I units (liquid phase units) and $5 \mu \mathrm{M} \mathrm{CPT}$ as positive control. Reactions were carried out in triplicate in solid phase. The inset gel shows a parallel set of reactions carried out under identical conditions, except the DNA products were analyzed on a $1 \%$ agarose-ethidium bromide gel. (C,D) Analysis of input DNA. Solid phase reactions contained 512 units of topo I and graded doses of linearized plasmid DNA (C) or Form I DNA (D) in the presence and absence of $10 \mu \mathrm{M}$ CPT. Reactions were carried out in triplicate. 

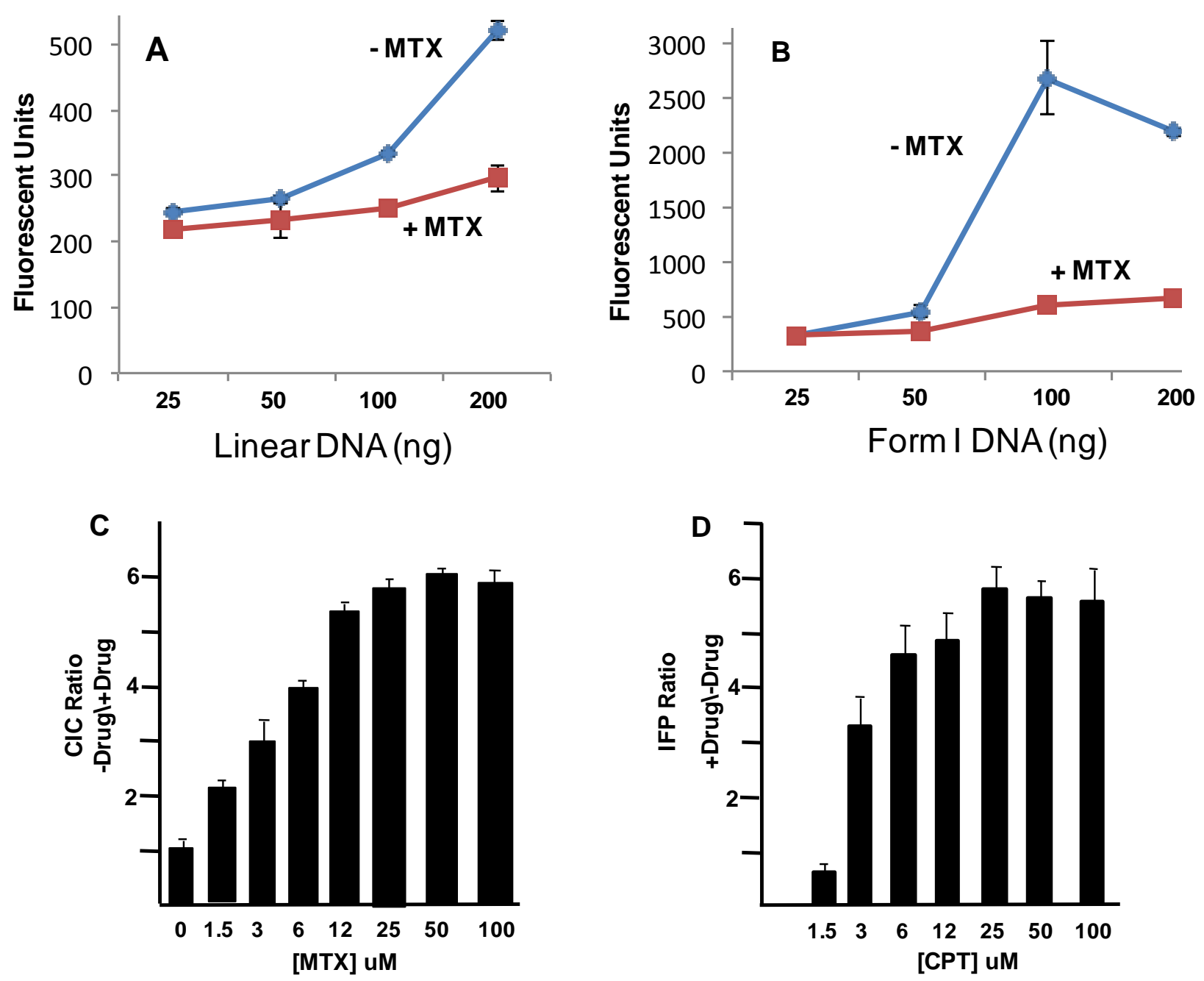

Figure 11: Optimized input DNA for detecting CIC. 
Figure 11: Optimized input DNA for detecting CIC.

(A) Input DNA testing. Solid phase reactions contained purified topo I (512 units) and either Form I DNA or linearized plasmid in the presence and absence of $10 \mu \mathrm{M}$ mitoxantrone (MTX). Reactions were in triplicate. (B) Reconstructed CIC titration with MTX. Titrations with the CIC drug (MTX) contained topo I (512 units) and 100 ng of Form I DNA. (C) Titrations with the IFP drug (CPT) were identical except 100 ng of linear DNA were used. The CIC ratio represents plus drug readout/no drug controls. The IFP ratio is the inverse or - drug/+drug. 
Table 2: Washing and Reaction conditions

\begin{tabular}{|l|l|l|}
\hline Condition $^{\mathrm{a}}$ & $-\mathrm{CPT}$ & $+\mathrm{CPT}$ \\
\hline Control $^{\mathrm{b}}$ & $100 \%$ & $100 \%$ \\
\hline $3 \mathrm{M} \mathrm{Gu}-\mathrm{HCl}$ & $100 \%$ & $100 \%$ \\
\hline $1 \mathrm{M} \mathrm{Urea}$ & $100 \%$ & $100 \%$ \\
\hline $25 \mathrm{ul}^{\mathrm{c}}$ & $100 \%$ & $100 \%$ \\
\hline $50 \mathrm{ul}$ & $66 \%$ & $100 \%$ \\
\hline $100 \mathrm{ul}$ & $40 \%$ & $37 \%$ \\
\hline $200 \mathrm{ul}$ & $23 \%$ & $24 \%$ \\
\hline $0 \mathrm{NaCl}$ & $100 \%$ & nd \\
\hline $0.1 \mathrm{M} \mathrm{NaCl}$ & $72 \%$ & nd \\
\hline $0.25 \mathrm{~N} \mathrm{NaCl}$ & $66 \%$ & nd \\
\hline $0.5 \mathrm{M} \mathrm{NaCl}$ & $58 \%$ & nd \\
\hline
\end{tabular}

${ }^{a}$ Reactions contained 512 units of topo I input, 100 ng Form I DNA and - or $+5 \mathrm{uM}$ CPT. The reactions were terminated and washed four times with buffers containing the indicated solutes or using standard assay washes (see Materials and Methods) with the indicated binding/reaction volumes. The values given correspond to the $\%$ of maximal observed value for each treatment (nd, not done).

${ }^{\mathrm{b}}$ Control represents the standard solid phase assay conditions for either - and or $+\mathrm{CPT}$ (actual fluorescent units 2150 and 3450 respectively).

c Volume experiments correspond to the volume used in the binding and assay in each well. 
Table 3: Screening of Natural product set by HTS

\begin{tabular}{|c|c|c|c|c|}
\hline Compound & $\begin{array}{l}\text { a CIC Ratio } \\
\text {-drug/+drug }\end{array}$ & $\begin{array}{l}\text { blnhibition } \\
\text { (@10 uM) }\end{array}$ & Compound & $\begin{array}{l}\text { c IFP Ratio } \\
\text { +drug/-drug }\end{array}$ \\
\hline Negative control & 1.0 & $0 \%$ & Negative control & - \\
\hline $\begin{array}{l}\text { Positive control } \\
\text { Mitoxantrone }\end{array}$ & $12.1^{\star *}$ & $85 \%$ & $\begin{array}{l}\text { Positive control } \\
\text { IFP (CPT) }\end{array}$ & $4.0^{* *}$ \\
\hline 1. Daunorubicin & 2.45 & $<10 \%$ & $\begin{array}{l}\text { d Positive control } \\
\text { CIC (MTX) }\end{array}$ & $0.40^{\star *}$ \\
\hline 2. Sporidesmolide & 1.86 & $0 \%$ & 8. Dactinomycin & $2.17^{*}$ \\
\hline \multirow[t]{2}{*}{ 3. Himbacine } & \multirow[t]{2}{*}{1.47} & \multirow[t]{2}{*}{$0 \%$} & 9. Irinotecan & $2.2^{*}$ \\
\hline & & & 10. Topotecan & $2.77^{\star}$ \\
\hline \multirow{2}{*}{$\begin{array}{l}\text { 4. Chrysanthin } \\
\text { Pyrethrosin }\end{array}$} & \multirow[t]{2}{*}{1.45} & \multirow[t]{2}{*}{$0 \%$} & 11. Tamoxifen & $2.17^{*}$ \\
\hline & & & 12. Ralaxofene & $2.0^{*}$ \\
\hline 5. Dehydroabietic acid & 1.42 & $0 \%$ & 13. Procarbazine & $2.0^{*}$ \\
\hline 6. Carbomycin & 1.33 & $0 \%$ & $\begin{array}{l}\text { 14. Nitrogen } \\
\text { mustard }\end{array}$ & 1.42 \\
\hline $\begin{array}{l}\text { 7. Fumagillin } \\
\text { dicyclohexylamine }\end{array}$ & 1.28 & $0 \%$ & $\begin{array}{l}\text { 15. Uracil } \\
\text { mustard }\end{array}$ & 1.12 \\
\hline
\end{tabular}

a. The natural product set II ( ID\# 1391250/87) was screened for CIC active agents that would score as catalytic inhibitors of topo I $(10 \mu \mathrm{M})$ using Form I DNA. Out of 94 compounds, only a single compound was statistically significant (mitoxantrone; $* * \mathrm{p}<$ 0.01). The other compounds listed allowed elevated targeting of topo I but inhibition was negative based on relaxation data.

b. Confirmations of CIC activity was tested by relaxation of plasmid DNA at three drug concentrations ( 1,10 and $100 \mu \mathrm{M})$. The $10 \mu \mathrm{M}$ result is shown.

c. Known topo poisons (brackets) were tested at $10 \mu \mathrm{M}$ with linearized plasmid DNA. The remaining compounds listed scored as IFP hits with the indicated $\mathrm{p}$ values $(* \mathrm{p}<0.05$, $* * \mathrm{p}<0.01)$ out of 94 compounds screened. The mustard compounds displayed elevated IFP ratios but were not statistically significant. 


\section{REFERENCES:}

1. Deweese, J.E., M.A. Osheroff, and N. Osheroff, DNA topology and topoisomerases. Biochemistry and Molecular Biology Education, 2009. 37(1): p. 2-10.

2. Wasserman, S.A. and N.R. Cozzarelli, Biochemical Topology: Applications to DNA Recombination and Replication. Science, 1986. 232(4753): p. 951-960.

3. Espeli, O. and K.J. Marians, Untangling intracellular DNA topology. Molecular Microbiology, 2004. 52(4): p. 925-931.

4. Crick, F.H., Linking numbers and nucleosomes. Proceedings of the National Academy of Sciences, 1976. 73(8): p. 2639-2643.

5. Fuller, F.B., The Writhing Number of a Space Curve. Proceedings of the National Academy of Sciences, 1971. 68(4): p. 815-819.

6. Witz, G. and A. Stasiak, DNA supercoiling and its role in DNA decatenation and unknotting. Nucleic Acids Research. 38(7): p. 2119-2133.

7. Koster, D.A., et al., Cellular Strategies for Regulating DNA Supercoiling: A SingleMolecule Perspective. Cell. 142(4): p. 519-530.

8. Brill, S.J., et al., Need for DNA topoisomerase activity as a swivel for DNA replication for transcription of ribosomal RNA. Nature, 1987. 326(6111): p. 414-416.

9. Earnshaw, W.C., et al., Topoisomerase II is a structural component of mitotic chromosome scaffolds. The Journal of Cell Biology, 1985. 100(5): p. 1706-1715.

10. Husain, I., et al., Elevation of Topoisomerase I Messenger RNA, Protein, and Catalytic Activity in Human Tumors: Demonstration of Tumor-type Specificity and Implications for Cancer Chemotherapy. Cancer Research, 1994. 54(2): p. 539-546.

11. Liu, L.F. and J.C. Wang, Supercoiling of the DNA template during transcription. Proceedings of the National Academy of Sciences, 1987. 84(20): p. 7024-7027. 
12. Woessner, R.D., et al., Proliferation- and cell cycle-dependent differences in expression of the 170 kilodalton and 180 kilodalton forms of topoisomerase II in NIH-3T3 cells. Cell Growth Differentiation, 1991. 2(4): p. 209-214.

13. Roca, J., Transcriptional inhibition by DNA torsional stress. Transcription, 2011. 2(2): p. 82-85.

14. Liu, L.F., et al., Cleavage of DNA by mammalian DNA topoisomerase II. Journal of Biological Chemistry, 1983. 258(24): p. 15365-15370.

15. Gellert, M., DNA Topoisomerases. Annual Review of Biochemistry, 1981. 50(1): p. 879910.

16. Maxwell, A.a.G., M., Mechanistic aspects of DNA topoisomerases. Adv. Protein Chemistry, 1986. 38: p. 69-107.

17. Corbett, K.D. and J.M. Berger, STRUCTURE, MOLECULAR MECHANISMS, AND EVOLUTIONARY RELATIONSHIPS IN DNA TOPOISOMERASES. Annual Review of Biophysics and Biomolecular Structure, 2004. 33(1): p. 95-118.

18. Gangloff, S., et al., The yeast type I topoisomerase Top3 interacts with Sgs1, a DNA helicase homolog: a potential eukaryotic reverse gyrase. Molecular and Cellular Biology, 1994. 14(12): p. 8391-8398.

19. Wang, J.C., Cellular roles of DNA topoisomerases: a molecular perspective. Nat Rev Mol Cell Biol, 2002. 3(6): p. 430-440.

20. Champoux, J.J., DNA TOPOISOMERASES: Structure, Function, and Mechanism. Annual Review of Biochemistry, 2001. 70(1): p. 369.

21. Bouthier de la Tour, C., et al., Reverse gyrase in thermophilic eubacteria. The Journal of Bacteriology, 1991. 173(12): p. 3921-3923.

22. Confalonieri, F., et al., Reverse gyrase: a helicase-like domain and a type I topoisomerase in the same polypeptide. Proceedings of the National Academy of Sciences, 1993. 90(10): p. 4753-4757. 
23. Berger, J.M., et al., Structural similarities between topoisomerases that cleave one or both DNA strands. Proceedings of the National Academy of Sciences, 1998. 95(14): p. 7876-7881.

24. Forterre, P., et al., Origin and evolution of DNA topoisomerases. Biochimie, 2007. 89(4): p. $427-446$.

25. Aravind, L., D.D. Leipe, and E.V. Koonin, Toprimâ€" a conserved catalytic domain in type IA and II topoisomerases, DnaG-type primases, OLD family nucleases and RecR proteins. Nucleic Acids Research, 1998. 26(18): p. 4205-4213.

26. Sissi, C. and M. Palumbo, Effects of magnesium and related divalent metal ions in topoisomerase structure and function. Nucleic Acids Research, 2009. 37(3): p. 702-711.

27. Rodriguez, A.C. and D. Stock, Crystal structure of reverse gyrase: insights into the positive supercoiling of DNA. EMBO J, 2002. 21(3): p. 418-426.

28. Berger, J.M., Structure of DNA topoisomerases. Biochimica et Biophysica Acta (BBA) Gene Structure and Expression, 1998. 1400(1-3): p. 3-18.

29. Lima, C.D., J.C. Wang, and A. Mondragon, Three-dimensional structure of the $67 \mathrm{~K} \mathrm{~N}$ terminal fragment of E. coli DNA topoisomerase I. Nature, 1994. 367(6459): p. 138-146.

30. Wang, J.C., DNA Topoisomerases. Annual Review of Biochemistry, 1996. 65(1): p. 635692.

31. Li, Z., A. Mondrag $\tilde{A}^{3} n$, and R.J. DiGate, The Mechanism of Type IA TopoisomeraseMediated DNA Topological Transformations. Molecular Cell, 2001. 7(2): p. 301-307.

32. Redinbo, M.R., J.J. Champoux, and W.G.J. Hol, Structural insights into the function of type IB topoisomerases. Current Opinion in Structural Biology, 1999. 9(1): p. 29-36.

33. Cheng, C., et al., Conservation of Structure and Mechanism between Eukaryotic Topoisomerase I and Site-Specific Recombinases. Cell, 1998. 92(6): p. 841-850. 
34. Mao, Y., Mehll, I., and Muller, M.T., Nuclear and Nucleolar Localization by the Nterminal Domain of DNA Topoisomerase I. Proc Natl Acad Sci USA, 2002(99): p. 12351240.

35. Stewart, L., G.C. Ireton, and J.J. Champoux, The Domain Organization of Human Topoisomerase I. Journal of Biological Chemistry, 1996. 271(13): p. 7602-7608.

36. Leppard, J.B. and J.J. Champoux, Human DNA topoisomerase I: relaxation, roles, and damage control. Chromosoma, 2005. 114(2): p. 75-85.

37. Krogh, B.O. and S. Shuman, Proton Relay Mechanism of General Acid Catalysis by DNA Topoisomerase IB. Journal of Biological Chemistry, 2002. 277(8): p. 5711-5714.

38. Redinbo, M.R., et al., Crystal Structures of Human Topoisomerase I in Covalent and Noncovalent Complexes with DNA. Science, 1998. 279(5356): p. 1504-1513.

39. Krogh, B.O. and S. Shuman, Catalytic Mechanism of DNA Topoisomerase IB. Molecular Cell, 2000. 5(6): p. 1035-1041.

40. Koster, D.A., et al., Friction and torque govern the relaxation of DNA supercoils by eukaryotic topoisomerase IB. Nature, 2005. 434(7033): p. 671-674.

41. Sari, L. and I. Andricioaei, Rotation of DNA around intact strand in human topoisomerase I implies distinct mechanisms for positive and negative supercoil relaxation. Nucleic Acids Research. 33(20): p. 6621-6634.

42. Carey, J.F., et al., DNA relaxation by human topoisomerase I occurs in the closed clamp conformation of the protein. Proceedings of the National Academy of Sciences, 2003. 100(10): p. 5640-5645.

43. Stewart, L., et al., A Model for the Mechanism of Human Topoisomerase I. Science, 1998. 279(5356): p. 1534-1541.

44. $\quad$ M T Muller, W.P.P., V B Mehta, and D K Trask, Eukaryotic type I topoisomerase is enriched in the nucleolus and catalytically active on ribosomal DNA. EMBO J, 1985. 4(5): p. 1237-1243. 
45. Froelich-Ammon, S.J. and N. Osheroff, Topoisomerase Poisons: Harnessing the Dark Side of Enzyme Mechanism. Journal of Biological Chemistry, 1995. 270(37): p. 2142921432.

46. Pouliot, J.J. and K.C. Yao, Yeast Gene for a Tyr-DNA Phosphodiesterase that Repairs Topoisomerase I Complexes. Science, 1999. 286(5439): p. 552.

47. Zhou, B.B. and S.J. Elledge, \{The DNA damage response: putting checkpoints in perspective\}. Nature, 2000. 408: p. 433-439.

48. Khanna, K.K. and S.P. Jackson, DNA double-strand breaks: signaling, repair and the cancer connection. Nature Genetics, 2001. 27(3): p. 247.

49. Rubbi, C.P. and J. Milner, Disruption of the nucleolus mediates stabilization of p53 in response to DNA damage and other stresses. EMBO J, 2003. 22(22): p. 6068-6077.

50. Mao, Y., I.R. Mehl, and M.T. Muller, Subnuclear Distribution of Topoisomerase I is Linked to Ongoing Transcription and p53 Status. Proceedings of the National Academy of Sciences of the United States of America, 2002. 99(3): p. 1235-1240.

51. Nelson, W.G. and M.B. Kastan, DNA strand breaks: the DNA template alterations that trigger p53-dependent DNA damage response pathways. Molecular and Cellular Biology, 1994. 14(3): p. 1815-1823.

52. Pommier, Y., et al., Mechanism of action of eukaryotic DNA topoisomerase I and drugs targeted to the enzyme. Biochimica et Biophysica Acta (BBA) - Gene Structure and Expression, 1998. 1400(1-3): p. 83-105.

53. Potmesil, M., et al., Resistance of Human Leukemic and Normal Lymphocytes to Druginduced DNA Cleavage and Low Levels of DNA Topoisomerase II. Cancer Research, 1988. 48(12): p. 3537-3543.

54. Ishida, R., et al., DNA Topoisomerase II Is the Molecular Target of Bisdioxopiperazine Derivatives ICRF-159 and ICRF-193 in Saccharomyces cerevisiae. Cancer Research, 1995. 55(11): p. 2299-2303. 
55. Wall, M.E., et al., Plant Antitumor Agents. I. The Isolation and Structure of Camptothecin, a Novel Alkaloidal Leukemia and Tumor Inhibitor from Camptotheca acuminatal,2. Journal of the American Chemical Society, 1966. 88(16): p. 3888-3890.

56. Hsiang, Y.-H. and L.F. Liu, Identification of Mammalian DNA Topoisomerase I as an Intracellular Target of the Anticancer Drug Camptothecin. Cancer Research, 1988. 48(7): p. 1722-1726.

57. Jaxel, C., et al., Structure-Activity Study of the Actions of Camptothecin Derivatives on Mammalian Topoisomerase I: Evidence for a Specific Receptor Site and a Relation to Antitumor Activity. Cancer Research, 1989. 49(6): p. 1465-1469.

58. Hsiang, Y.H., et al., Camptothecin induces protein-linked DNA breaks via mammalian DNA topoisomerase I. Journal of Biological Chemistry, 1985. 260(27): p. 14873-14878.

59. Yaw-Huei Hsiang, R.H., Sidney Hecht, and Leroy F. Liu, Camptothecin induces proteinlinked DNA breaks via mammalian DNA topoisomerase I. Journal of Biological Chemistry. The Journal of Biological Chemistry, 1985. 260(25): p. 14878.

60. Avemann, K., et al., Camptothecin, a specific inhibitor of type I DNA topoisomerase, induces DNA breakage at replication forks. Molecular and Cellular Biology, 1988. 8(8): p. 3026-3034.

61. Liu, L.F., DNA Topoisomerase Poisons as Antitumor Drugs. Annual Review of Biochemistry, 1989. 58(1): p. 351-375.

62. D'Arpa, P., C. Beardmore, and L.F. Liu, Involvement of Nucleic Acid Synthesis in Cell Killing Mechanisms of Topoisomerase Poisons. Cancer Research, 1990. 50(21): p. 69196924.

63. Mao, Y. and M.T. Muller, Down modulation of topoisomerase I affects DNA repair efficiency. DNA Repair, 2003. 2(10): p. 1115-1126.

64. Mao, Y., et al., SUMO-1 conjugation to topoisomerase I: A possible repair response to topoisomerase-mediated DNA damage. Proceedings of the National Academy of Sciences, 2000. 97(8): p. 4046-4051. 
65. Desai, S.D., et al., Ubiquitin-dependent Destruction of Topoisomerase I Is Stimulated by the Antitumor Drug Camptothecin. Journal of Biological Chemistry, 1997. 272(39): p. 24159-24164.

66. Beretta, G.L., P. Perego, and F. Zunino, Mechanisms of Cellular Resistance to Camptothecins. Current Medicinal Chemistry, 2006. 13(27): p. 3291-3305.

67. Chen, A.Y. and L.F. Liu, DNA Topoisomerases: Essential Enzymes and Lethal Targets. Annual Review of Pharmacology and Toxicology, 1994. 34(1): p. 191-218.

68. Subramanian, D., C.S. Furbee, and M.T. Muller, ICE Bioassay, in DNA Topoisomerase Protocols : Volume II: Enzymology and Drugs. 2000. p. 137-147.

69. Muller, M.T., Quantitation of eukaryotic topoisomerase I reactivity with DNA. Preferential cleavage of supercoiled DNA. Biochimica et Biophysica Acta (BBA) - Gene Structure and Expression, 1985. 824(3): p. 263-267.

70. Trask, D.K. and M.T. Muller, Stabilization of type I topoisomerase-DNA covalent complexes by actinomycin D. Proceedings of the National Academy of Sciences, 1988. 85(5): p. 1417-1421.

71. Maxwell, A., N.P. Burton, and N. O'Hagan, High-throughput assays for DNA gyrase and other topoisomerases. Nucleic Acids Research. 34(15): p. e104-e104.

72. Shapiro, A., et al., A Homogeneous, High-Throughput Fluorescence Anisotropy-Based DNA Supercoiling Assay. Journal of Biomolecular Screening. 15(9): p. 1088-1098.

73. Tsai, H.-P., et al., Immobilizing topoisomerase I on a surface plasmon resonance biosensor chip to screen for inhibitors. Journal of Biomedical Science. 17(1): p. 49.

74. Stewart, L. and J.J. Champoux, Purification of Baculovirus-Expressed Human DNA Topoisomerase I. 1999. p. 223-234.

75. Zhang, J.-H., T.D.Y. Chung, and K.R. Oldenburg, A Simple Statistical Parameter for Use in Evaluation and Validation of High Throughput Screening Assays. Journal of Biomolecular Screening, 1999. 4(2): p. 67-73. 
76. Trask, D.K. and M.T. Muller, Biochemical characterization of topoisomerase I purified from avian erythrocytes. Nucleic Acids Research, 1983. 11(9): p. 2779-2800.

77. Loughran, S.T. and D. Walls, Purification of Poly-Histidine-Tagged Proteins, in Protein Chromatography. p. 311-335.

78. Wassermann, K., et al., Effects of morpholinyl doxorubicins, doxorubicin, and actinomycin D on mammalian DNA topoisomerases I and II. Molecular Pharmacology, 1990. 38(1): p. 38-45.

79. Larosche, I., et al., Tamoxifen Inhibits Topoisomerases, Depletes Mitochondrial DNA, and Triggers Steatosis in Mouse Liver. Journal of Pharmacology and Experimental Therapeutics, 2007. 321(2): p. 526-535. 